\title{
Antimicrobial activity of Tachyplesin 1 against Burkholderia pseudomallei: an in vitro and in silico approach
}

\author{
Lyn Fay Lee ${ }^{\text {Corresp.. }}{ }^{1}$, Vanitha Mariappan ${ }^{1}$ ， Kumutha Malar Vellasamy ${ }^{1}$, Vannajan Sanghiran Lee ${ }^{2}$, Jamuna \\ Vadivelu $^{1}$ \\ ${ }^{1}$ Department of Medical Microbiology, Faculty of Medicine, University of Malaya, Kuala Lumpur, Malaysia \\ 2 Department of Chemistry, Faculty of Science, University of Malaya, Kuala Lumpur, Malaysia \\ Corresponding Author: Lyn Fay Lee \\ Email address: lynfay.lee13@gmail.com
}

Burkholderia pseudomallei , the causative agent of melioidosis, is intrinsically resistant to many conventional antibiotics. Therefore, alternative antimicrobial agents such as antimicrobial peptides (AMPs) are extensively studied to combat this issue. Our study aims to identify and understand the mode of action of the potential AMP(s) that are effective against $B$. pseudomallei in both planktonic and biofilm state as well as to predict the possible binding targets on using in vitro and in silico approaches. In the in vitro study, 11 AMPs were tested against $100 \mathrm{~B}$. pseudomallei isolates for planktonic cell susceptibility, where LL-37, and PG1, demonstrated $100.0 \%$ susceptibility and TP1 demonstrated $83 \%$ susceptibility . Since the $B$. pseudomallei activity was reported on LL-37 and PG1, TP1 was selected for further investigation. TP1 inhibited B. pseudomallei cells at $61.69 \mu \mathrm{M}$, and membrane blebbing was observed using scanning electron microscopy . Moreover, TP1 inhibited B. pseudomallei cell growth, reaching bactericidal endpoint within 2 hours post exposure as compared to ceftazidime ( 8 hours). Furthermore, TP1 was shown to suppress the growth of $B$. pseudomallei cells in biofilm state at concentrations above $221 \mu \mathrm{M}$. However, TP1 was cytotoxic to the mammalian cell lines tested. In the in silico study, molecular docking revealed that TP1 demonstrated a strong interaction to the common peptide or inhibitor binding targets for lipopolysaccharide of Escherichia coli, as well as autolysin, pneumolysin, and pneumococcal surface protein A ( P spA) of Streptococcus pneumoniae. Homology modelled B. pseudomallei PspA protein (YDP) also showed a favourable binding with a strong electrostatic contribution and nine hydrogen bonds . In conclusion, TP1 demonstrated a good potential as an anti-B. pseudomallei agent. 


\section{PeerJ}

1

2

3

4

5 Lyn-Fay Lee ${ }^{1}$, Vanitha Mariappan ${ }^{1}$, Kumutha-Malar Vellasamy ${ }^{1}$, Vannajan-Sanghiran Lee ${ }^{2}$,

6

7

8

$9 \quad$ Kuala Lumpur, Malaysia

$10{ }^{2}$ Department of Chemistry, Faculty of Science, University Malaya, 50603 Kuala Lumpur,

11 Malaysia

12

13

14

15

16

$17 *$ Corresponding author:

18 Jamuna Vadivelu

19 Department of Medical Microbiology,

20 Faculty of Medicine,

21 University of Malaya,

22

23

24

25

26

\section{pseudomallei: an in vitro and in silico approach}

JamunaVadivelu $^{1 *}$

\section{Manuscript to be reviewed}




\section{Manuscript to be reviewed}

\section{ABSTRACT}

28 Burkholderia pseudomallei, the causative agent of melioidosis, is intrinsically resistant to many

29

30

31

32 conventional antibiotics. Therefore, alternative antimicrobial agents such as antimicrobial peptides (AMPs) are extensively studied to combat this issue. Our study aims to identify and understand the mode of action of the potential $\operatorname{AMP}(\mathrm{s})$ that are effective against $B$. pseudomallei in both planktonic and biofilm state as well as to predict the possible binding targets on using in vitro and in silico approaches. In the in vitro study, 11 AMPs were tested against 100 B. pseudomallei isolates for planktonic cell susceptibility, where LL-37, and PG1, demonstrated $100.0 \%$ susceptibility and TP1 demonstrated $83 \%$ susceptibility. Since the $B$. pseudomallei activity was reported on LL-37 and PG1, TP1 was selected for further investigation. TP1 inhibited B. pseudomallei cells at $61.69 \mu \mathrm{M}$, and membrane blebbing was observed using scanning electron microscopy. Moreover, TP1 inhibited B. pseudomallei cell growth, reaching bactericidal endpoint within 2 hours post exposure as compared to ceftazidime ( 8 hours). Furthermore, TP1 was shown to suppress the growth of B. pseudomallei cells in biofilm state at concentrations above $221 \mu \mathrm{M}$. However, TP1 was cytotoxic to the mammalian cell lines tested. In the in silico study, molecular docking revealed that TP1 demonstrated a strong interaction to the common peptide or inhibitor binding targets for lipopolysaccharide of Escherichia coli, as well as autolysin, pneumolysin, and pneumococcal surface protein A (PspA) of Streptococcus pneumoniae. Homology modelled B. pseudomallei PspA protein (YDP) also showed a favourable binding with a strong electrostatic contribution and nine hydrogen bonds. In conclusion, TP1 demonstrated a good potential as an anti- $B$. pseudomallei agent. 


\section{Manuscript to be reviewed}

\section{INTRODUCTION}

51 Burkholderia pseudomallei, the causative agent for melioidosis, is commonly found in the soil

52 and water of Southeast Asia, and Northern Australia (Cheng \& Currie 2005). Due to the ease of dissemination where infection can be acquired either through an open wound, inhalation, or ingestion (Puthucheary 2009), coupled with the genomic plasticity of the bacteria (Holden et al. 2004; Schweizer 2012b), it is labelled as a potential biological warfare agent and classified as a category B bio threat agent by Centers for Disease Control and Prevention where specific enhancements are required for diagnostic capacity and disease surveillance (Stockel et al. 2015). Currently, melioidosis is treated using parenteral therapy of ceftazidime (CAZ) followed by prophylactic therapy of co-trimoxizole (Dance 2014a). Over the years, B. pseudomallei has been reported to resist the commonly used antibiotics (increased usage of CAZ and amoxicillin/clavulanic acid in treatment), and also to the ability to form biofilm in vitro and in vivo (Schweizer 2012a). To exacerbate the problem, incomplete treatment resulted in a high rate of melioidosis relapse. Worst of all, despite appropriate antimicrobial therapy, mortality from melioidosis septic shock remained high (Wiersinga et al. 2006). As such, there is a need to consider alternative antimicrobial agents, one of which is the antimicrobial peptides (AMPs)(Rotem \& Mor 2009).

AMPs, both naturally occurring and synthetic, have considerable advantages for therapeutic applications, including broad-spectrum activity, rapid onset of activity and relatively low possibility of emergence of resistance (Seo et al. 2012). Furthermore, they act on slow-growing or even non-growing bacteria due to the ability to permeablise and form pores within the cytoplasmic membrane (Batoni et al. 2011). Groups of AMP's i.e., defensins, cathelicidins, and dermicins have previously been reported to show potential against various pathogens (Wiesner \& Vilcinskas 2010). However, to date, only a few cathelicidin AMPs have been 


\section{Manuscript to be reviewed}

75 reported to be effective against B. pseudomallei, including LL-37 (Kanthawong et al. 2012),

76

77

78

79

protegrin 1 (PG1) (Sim et al. 2011), bovine lactoferrin (Puknun et al. 2013), phospholipase A2 inhibitors (Samy et al. 2015), and sheep cathelicidin (SMAP-29)(Blower et al. 2015).

To compliment in vitro investigations, in silico investigations were incorporated to elucidate the mechanism of action of the potential antimicrobial compounds. As structures of more protein targets become available through crystallography, nuclear magnetic resonance (NMR) and bioinformatics methods, there is an increasing demand for computational tools that can identify and analyse active sites and suggest potential drug molecules that can specifically bind to these sites. This gives rise to various docking programs such as DOCK, GLIDE, and Surfle which predict the preferred orientation of a drug (ligand) molecule to a receptor molecule when bound to each other to form a stable complex (Kitchen et al. 2004; Lengauer \& Rarey 1996) and also the strength of association or binding affinity between both the molecules. (Cross et al. 2009). The in silico methods allow drug-ligand interaction studies to be performed in shorter time periods and aids the designing of better therapeutic compounds (Gupta et al. 2013; Kapetanovic 2008). Incorporation of both in vivo and in silico techniques has been widely used in the recent years. Le et al. (2015) performed toxicity studies together with molecular docking to predict possible binding targets of $\mathrm{AMP} \mathrm{DM}_{3}$ using Autodock Vina where a strong affinity was demonstrated towards three targets; Streptococcus pneumoniae virulence factors; autolysin, pneumolysin, and pneumococcal surface protein A (PspA). In another study by Sarojini et al. (2010), in silico molecular docking using Autodock 3.0 was carried out to support the in vitro antibacterial and antifungal activity as well as to determine the orientation of the 2,5-dichloro thienyl substituted thiazole derivatives (4a-4d) bound in the active site of 3-deoxyD-glucosamine (GlcN)-6-P synthase (target for antifungals). Similar use of in silico molecular docking to compliment the findings of the in vitro/in vivo experiments and elucidate the 


\section{Manuscript to be reviewed}

100

101

102

103

104

105

106

107

108

109

110

111

112

113

114

115

116

117

118

119

120

121

122

123

antimicrobial-protein interaction was also been reported in a study by in Alves et al. (2013) on the antimicrobial properties of mushroom phenolic compounds and Al-Sohaibani \& Murugan (2012) on the inhibition effects of Salvadora persica on Streptococcus mutans.

Taking into account the effectiveness of AMPs to inhibit potentially antibiotic resistant bacteria, our study aimed to identify the potential AMP (s) that are effective against $B$. pseudomallei in both planktonic and biofilm state and to predict the possible binding targets on B. pseudomallei protein structures. Overall, there were two approaches in this study; in vitro and in silico. Initially, the in vitro experiments were executed to identify the potential AMP(s) that are effective against B. pseudomallei in both planktonic and biofilm state. Based on those observations, the in silico experiments were then carried out on the selected AMP to predict the possible binding targets on the available B. pseudomallei protein structures. Both of these approaches will assist in elucidating the action of the AMP on B. pseudomallei and contribute to the development of AMPs as an alternative anti- B. pseudomallei agent.

\section{MATERIALS AND METHODS}

\section{Bacteria strains and growth conditions}

A total of 90 B. pseudomallei clinical isolates from melioidosis patients (archive collection of University of Malaya Medical Centre (UMMC), Kuala Lumpur and Hospital Tengku Ampuan Afzan, Pahang) and 10 non-clinical isolates (one environmental and nine animal) were included in this study. All isolates were identified as B. pseudomallei using routine phenotypic characterization including selective growth on Ashdown, biochemical profiles on API 20 NE tests (BioMérieux, France) and in-house polymerase chain reaction (PCR) analysis (Suppiah et al. 2010). Prior to the study, the B. pseudomallei isolates were cultured aerobically in Luria 


\section{Manuscript to be reviewed}

124 Bertani (LB) broth at $37^{\circ} \mathrm{C}$ and agitated at $180 \mathrm{rpm}$ for 24 hours according to Al-Maleki et al. 125 (2014).

126

127 Peptide storage and handling

128 A total of 11 AMPs used in this study were selected based on the potential to inhibit other 129 Gram-negative organisms; LL-37, Magainin 2, Tachyplesin 1 (TP1), PG1, Sushi 1, Sushi 2, 130 1037, 1018, DJK5, V2D, and ornithine. Among these LL-37, Magainin 2, TP1, and PG1 were synthesized by SBS Genetech, China; Sushi 1 and Sushi 2 were synthesised by First Base Laboratories, Singapore; Peptide 1037, 1018, and DJK5 were kindly provided by our collaborators from University of British Columbia, Canada; while V2D and ornithine were provided by our collaborators in National University of Singapore (Table 1).

The AMPs used in this study were stored in lyophilized form at $-20^{\circ} \mathrm{C}$ (Kraut et al. 2009), and were dissolved with DNAase/ RNAse-free distilled water (for all AMPs except sushi peptides), and $0.5 \%(\mathrm{v} / \mathrm{v})$ of dimethyl sulfoxide (DMSO; for both Sushi peptides). Once dissolved, the AMPs were stored in glass vials in aliquots of $200 \mu \mathrm{l}$ at a concentration of $10 \mathrm{mg} / \mathrm{ml}$. The AMPs were diluted in $0.01 \%$ acetic acid containing $0.2 \%$ bovine serum albumin (BSA) for the preliminary screening whereas the dilution of AMPs with serum free Roswell Park Memorial Institute 1640 media (RPMI 1640; Life Technologies) was performed to minimize the dilution of the RPMI used in subsequent experiments. In addition, the microtiter plates used in this study were made of polypropylene while the storage vials were made of polypropylene (Hancock 1999). 
149 The 100 strains mentioned were screened for AMP susceptibility by colony counting

150 (Sieuwerts et al. 2008). The 11 AMPs were diluted to $1 \mathrm{mg} / \mathrm{ml}$ before use. Screening was

151 performed as described previously (Sheafor et al. 2008) with slight modifications. Briefly, 80

$152 \mu$ of 24-hour B. pseudomallei culture in LB broth was diluted with $1 \mathrm{X}$ phosphate buffer saline

153 (PBS; $\mathrm{pH} 7.4$ ) to a bacteria density of $10^{5} \mathrm{CFU} / \mathrm{ml}$ and mixed with $20 \mu \mathrm{AMPs}$ prior to 154 incubation. The mixture was then plated on fresh nutrient agar (NA) and incubated at $37^{\circ} \mathrm{C}$ for 15524 hours to determine viability of the bacteria. Isolates were categorized as "sensitive" when 156 no growth was observed and categorized as "resistant" if there one or more colonies grown 157 after 24-hour incubation on NA. Three biological replicates were performed.

Minimum inhibitory concentration (MIC) and minimum bactericidal concentration (MBC) of AMPs on B. pseudomallei cells in planktonic state

Based on the preliminary screening results TP1 that inhibited B. pseudomallei, was selected for further study with LL-37 and PG1. In this study, B. pseudomallei strain K96243 and randomly selected $B$. pseudomallei clinical strains UMC031, UMC080, and UMC089, and Escherichia coli (ATCC 29522; control), were exposed to TP1, LL-37, and PG1 concentrations ranging from $0 \mu \mathrm{M}$ to $200 \mu \mathrm{M}$, with two-fold increase. The exponential phase culture of planktonic B. pseudomallei was centrifuged at $10,000 \mathrm{rpm}$ for 15 minutes to pellet the bacteria. The resulting pellet was washed three times with PBS and the bacterial density was adjusted to a $10^{5} \mathrm{CFU} / \mathrm{ml}$ using serum free RPMI 1640 medium; as recommended by Schwab et al. 1999 in order to obtain the highest AMP activity. A total of $20 \mu \mathrm{l}$ of each AMPs were added to 180 $\mu \mathrm{l}$ of the bacterial suspension in 96 well U-bottom microtiter plates (Eppendorf, USA). Following incubation at $37^{\circ} \mathrm{C}$ for 24 hours, the plates were subjected to optical density (OD) measurement at $570 \mathrm{~nm}$ using a microplate absorbance reader (Tecan Sunrise ${ }^{\mathrm{TM}}$, Switzerland) using the settings for U-bottom microtiter plates. Each well was subjected to a 10 times serial 
dilution and plated on NA to determine the viability of the bacteria (Sieuwerts et al. 2008). The

175

176

177

MIC was read as the lowest concentration of AMP that inhibited visible growth of the bacteria (Schwab, 1999) compared to the untreated after 24- hour incubation. Additionally, the MBC was determined when no growth was observed on NA following 24-hour incubation. Three technical replicates were performed on three different occasions.

\section{Time-kill kinetic assay of B. pseudomallei}

The time-kill kinetic assay was carried out with a similar set up as the MIC and MBC studies using B. pseudomallei strain K96243. Briefly, $20 \mu \mathrm{l}$ of AMP (TP1 at $55 \mu \mathrm{M}, 110 \mu \mathrm{M}$, and 221 $\mu \mathrm{M}$; approximately the MIC and MBC of B. pseudomallei strains tested) was added to $180 \mu \mathrm{l}$ of the bacterial suspension in a 96 well U-bottom microtiter plates. The plates were incubated $37^{\circ} \mathrm{C}$ for 24 hours and the absorbance was taken at OD $570 \mathrm{~nm}$ using the settings for U-bottom microtiter plates at 60-minute interval. At every two hours, the bacterial suspension in each well was subjected to a 10 times serial dilution and plated on NA to determine bacteria viability (Sieuwerts et al. 2008). In addition, the inhibition patterns of TP1 was also compared with 54 $\mu \mathrm{M}$ of ceftazidime (CAZ) $(30 \mu \mathrm{g} / \mathrm{ml}$; equivalent to the concentration on the antibiotic disk; Oxoid, UK), and also the untreated bacteria. Three technical replicates were performed on three different occasions, and the data obtained were analyzed with one-way Anova followed by Dunnett's test to determine the significance relative to the untreated bacteria $(\mathrm{P}<0.05)$.

\section{Inhibition activity of AMPs against B. pseudomallei in biofilm state}

B. pseudomallei K96243 was grown using a modification of the Calgary Biofilm Device; (Kanthawong et al. 2012) also known as minimum biofilm eradication concentration (MBEC) assay (Innovotech, Canada). To test the inhibition activity in biofilm state, $B$. pseudomallei K96243 was exposed to $1 \mathrm{mg} / \mathrm{ml}$, of the 11 tested AMPs including CAZ (30 $\mu \mathrm{g} / \mathrm{ml} ; 54 \mu \mathrm{M})$ and 


\section{Manuscript to be reviewed}

199

200

201

202

203

204

205

206

207

208

209

210

211

212

213

214

215

216

217

218

219

220

221

222

223

meropenem MRP $(10 \mu \mathrm{g} / \mathrm{ml} ; 26 \mu \mathrm{M})$. Both antibiotics were equivalent to the concentrations on the antibiotic disks (Oxoid, UK). In addition, TP1 at concentrations ranging from $55 \mu \mathrm{M}$ to $2649 \mu \mathrm{M}$ (with two-fold increase) were also tested against B. pseudomallei K96243 biofilm. Briefly, $150 \mu \mathrm{l}$ of B. pseudomallei culture (approximately $10^{5} \mathrm{CFU} / \mathrm{ml}$ ) was inserted into individual wells of the MBEC assay plate before incubation at $37^{\circ} \mathrm{C}$ for 16 hours. Following incubation, the biofilms were rinsed into microtiter plates containing PBS and then transferred into a new micro titre plate containing the antimicrobial agents tested in serum-free RPMI (antimicrobial challenge plates) before incubation at $37^{\circ} \mathrm{C}$ for 24 hours. Following these, the biofilms were disrupted using a water bath sonicator (Thermoline Scientific, Australia) for 30 minutes in PBS and the viability of the bacteria from the biofilm (CFU/biofilm) was determined by colony counting (Sieuwerts et al. 2008). Three biological replicates were performed, and the data obtained were analysed with one-way Anova followed by Dunnett's test to determine the significance relative to the untreated bacteria $(\mathrm{P}<0.05)$.

\section{Scanning Electron Microscopy (SEM)}

SEM was performed according to Song et al. (2012) with slight modifications. Briefly, $B$. pseudomallei K96243 culture was incubated with $62 \mu \mathrm{M}$ of TP1 at $37{ }^{\circ} \mathrm{C}$ for 24 hours. Following centrifugation $\left(10 \mathrm{~min}\right.$ at $\left.2000 \times g, 4{ }^{\circ} \mathrm{C}\right)$, the bacterial pellet was washed twice with PBS, and resuspended in $3.0 \%$ glutaraldehyde (incubated overnight at ambient temperature). Subsequently, the solution was rinsed three times with double distilled water and dehydrated in a graded series of ethanol solutions. After critical-point drying and layering with $20 \mathrm{~nm}$ gold coating (Leica EM SCD005, Leica Microsystems, Singapore), the microscopic analysis was performed using Quanta 650 FEG Scanning Electron Microscope (FEI, Oregon, USA). Both B. pseudomallei K96243 cell suspension without the AMPs and E. coli were treated as the control. 


\section{Manuscript to be reviewed}

\section{Cytotoxicity of AMPs on Mammalian Cell lines}

225 In this study, human lung epithelial (A549; ATCC $\left(\right.$ CCL185 ${ }^{\mathrm{TM}}$ ), human gastric 226 adenocarcinoma (AGS; ATCC® CRL-1739TM) and human hepatocellular carcinoma (HepG2; 227 ATCC ${ }^{\circledR}$ HB8065 ${ }^{\mathrm{TM}}$ ) cell lines were cultured in RPMI 1640 containing foetal bovine serum 228 (FBS) $(10 \%)$ at $37^{\circ} \mathrm{C}$ with $5 \% \mathrm{CO}_{2}$ and $95 \%$ relative humidity). Cytotoxicity was determined based on the reduction of 3- [4, 5-dimethylthiazol-2-yl]-2, 5 diphenyl tetrazolium bromide (MTT; Sigma, USA) by cellular oxidoreductases of viable cells, which yields a crystalline blue formazan product (Hansen et al. 2012). Briefly, cells (approximately 2 x $10^{4}$ cells/well) were seeded in tissue culture treated 96-well plates (Corning, USA). After 24 hours, the cells were rinsed with PBS and $200 \mu \mathrm{g} / \mathrm{ml}$ of the TP1 $(110 \mu \mathrm{M})$, PG1 $(115 \mu \mathrm{M})$ and LL-37 $(55 \mu \mathrm{M})$ were added as a solution in fresh serum free medium to a final volume of $100 \mu \mathrm{l} /$ well, respectively. Following 2 hours of incubation, the MTT reagent $(20 \mu \mathrm{l})$ was added to obtain a final concentration of $500 \mathrm{mg} / \mathrm{l}$ and further incubated for 3 hours. After which DMSO (solubilizing solution) was added to lyse the cells and to dissolve the formazan crystals and the absorbance was recorded at OD 570nm. The percentage of viable cells was calculated as followed:

(Absorbance of peptide treated cells)/ (Absorbance of untreated cells) x 100

Three technical replicates were performed on three different occasions, and the data obtained were analysed with one-way Anova followed by Dunnett's test to determine the significance relative to the untreated bacteria $(\mathrm{P}<0.05)$. The AMPs effect on the cell lines were also compared to MRP $(26 \mu \mathrm{M})$, and CAZ $(54 \mu \mathrm{M})$.

Possible TP1 interactions with protein targets from in silico molecular docking study Preparation of TP1 structure from PDB 


\section{Manuscript to be reviewed}

249 Solution NMR structures of TP1 (PDB ID: 2RTV) were obtained from Protein Data Bank

250 (PDB) (http://www.rcsb.org/pdb). The first model of 20 peptide configuration models available

251 in the PDB file was used. Prior to docking, AutoDock tools 4.2.6 (ADT) software was used to

252 prepare the ligand before proceeding to energy minimization using Accelrys Discovery Studio

253 2.5.5 (DS) software (Accelrys Software Inc., San Diego, CA, USA). The backbone of TP1 was

254 kept rigid whereas most of the side chains were defined as flexible in molecular docking

255 experiment.

256

257 Interaction of TP1 on selected bacteria structures

258 A total of four bacteria structures were selected to visualize TP1 interaction; lipopolysaccharide

259 (LPS) of E. coli, and Streptococcus pneumoniae proteins; autolysin, pneumolysin, and pneumococcal surface protein A (PspA).

261

262

TP1 has been reported to bind to the LPS of E. coli (Kushibiki et al. 2014). However, the LPS structure of B. pseudomallei is yet to be reported. Thus, the LPS model from E. coli was used to predict the interaction of TP1 with B. pseudomallei as both are Gram-negative bacteria and E. coli is often used as a representative for Gram negative bacteria (Fernandez-Recio et al. 2004; Galdiero et al. 2012). The molecular docking study was carried out with the prepared TP1 structure and the LPS structure of E. coli (PDB ID: 1QFG) based on Kushibiki et al. (2014) with a slight modification to add the missing atoms (e.g. hydrogens) in the model. The initial structure was modified according to the CHARMm force field with partial charge MomanyRone (Momany \& Rone 1992) and minimizations of the structures were performed, satisfying the root mean squared gradient tolerance of $0.1000 \mathrm{kcal} /$ (mol x Angstrom) before docking was carried out using AutodockVina (ADV) (Trott \& Olson 2010) instead of Autodock 4.2 as 
published. A $70 \times 80 \times 80$-point grid box of the structure was then generated with a grid spacing

of $0.375 \AA$, and centred on GlcN II in lipid A between TP1 and the LPS structure.

275

TP1 was reported to bind to both Gram negative and Gram positive bacteria (Imura et al. 2007;

Ohta et al. 1992) but to date, the binding activity on S. pneumoniae proteins was yet to be documented. As previously reported by (Le et al. 2015), three possible $S$. pneumoniae proteins targets for antimicrobial activities were autolysin, pneumolysin, and PspA (virulence factors). 1GVM), pneumolysin and PspA according to Le et al. (2015). The binding sites for the three molecules were defined as; autolysin at chain B: LYS258-ALA277, for pneumolysin at ARG426-ARG437, for PspA at GLY577-LEU588. The minimizations of these structures were carried out with a similar protocol as LPS of E. coli. A $40 \times 40 \times 40$-point grid box of the structure was then generated with a grid spacing of $0.375 \AA$, and centred at the respective binding sites. For all four structures, the interaction energies (IE; the summation of van der Waals' (VDW) and Electrostatic interaction energies) were investigated between TP1 and the structures using DS software. A low (negative) interaction energy between TP1 and the bacterial structures indicates a stable system and thus likely to bind. In addition, the software was also used to detect intermolecular hydrogen $\left(\mathrm{H}^{+}\right)$bonds and hydrophobic interactions which play a role in stabilizing the docked complex.

\section{Interaction of TP1 on homology modelled B. pseudomallei protein structure}

294 At this stage, all the three S. pneumoniae proteins demonstrated negative interaction energies with TP1 which indicated a strong interaction. When we searched for the protein sequences (BLAST search; blastp; non-redundant proteins with $95 \%$ sequence similarity) for all the 3 protein structures against $B$. pseudomallei protein sequence database, only the PspA sequence 
secured a hit in the search; YD repeat-containing protein (accession: CFU00865). This may

299

300

301

302

303

304

305

306

307

308

309

310

311

312

313

314

315

316

317

318

319

320

321

322

indicate that there are high similarities in the proteins of the Gram positive and Gram negative bacteria. Similarly, Alloing et al. (1990) have also demonstrated that the Ami proteins of $S$. pneumoniae exhibited homology with components of the oligopeptide permeases of the Gramnegative Salmonella typhimurium and E. coli. In addition, autolysin exists in the peptidoglycan bacterial cell walls, which applies to both Gram positive and Gram negative bacteria (Beveridge 1999). Thus, it is possible to execute homology modelling using the protein sequences of either Gram-positive or Gram-negative due to the similarities between both groups of bacteria. Taking into consideration of the above points, we have carried out homology modelling of the B. pseudomallei protein using PspA as a template.

Using DS, multiple sequence alignment was performed and the model was built using MODELLER function. The overall quality of the minimized model was evaluated by utilizing PROCHECK (Laskowski et al. 1993) for evaluation of Ramachandran plot quality, ERRAT (Colovos \& Yeates 1993) to verify patterns of non-bonded atomic interactions, and VERIFY3D (Luthy et al. 1992) for assessing the compatibility of each amino acid residue. Subsequently with ADV, TP1 was docked onto the YDP model using the binding site of PspA as a reference in order to predict the intermolecular interaction.

\section{RESULTS}

Preliminary screening of AMPs antimicrobial activity on B. pseudomallei isolates from Malaysia

A total of 100 B. pseudomallei isolates including the reference strain B. pseudomallei K96243 was subjected to colony counting after the exposure to the AMPs. Eighty-three strains (83\%) were susceptible to TP1 whereas 100 strains (100\%) were susceptible to both PG1 and LL-37. The isolates were $100 \%$ resistant to the remainder AMPs. In addition, there was no correlation 


\section{Manuscript to be reviewed}

323 between the AMP activity profiles and the antibiotic susceptibility data available

324 (Supplementary 1 and 2).

325

326 Based on the observation, although TP1 did not completely inhibit all the tested $B$. 327 pseudomallei isolates as seen with both LL-37 and PG1, it still was able to inhibit the isolates compared to the remainder eight AMPs which did not inhibit the tested isolates. Here, TP1 demonstrated the highest inhibition potential, comparable to LL-37 and PG1. To date, $B$. pseudomallei susceptibility to the eight non-responsive AMPs is yet to be reported whereas there were reports of B. pseudomallei susceptibility to LL-37 (Kanthawong et al. 2012), and PG1 (Sim et al. 2011). As such, TP1 was selected for further investigations in order to suggest its efficacy in comparison with both LL-37 and PG1.

\section{MIC and MBC on planktonic B. pseudomallei cells}

The MIC of TP1 $(61.69 \mu \mathrm{M})$ was threefold lower than its MBC $(193.35 \mu \mathrm{M})$. Relative to the MIC of TP1, MIC levels of LL37 $(47.29 \mu \mathrm{M})$ and PG1 $(15.46 \mu \mathrm{M})$ were approximately 1.3 and four-fold lower, respectively (Table 2). Similarly, the MBC of TP1 demonstrated two-fold and 12-fold higher levels compared to LL37 (92.73 $\mu \mathrm{M})$ and PG1 (15.46 $\mu \mathrm{M})$, respectively.

Overall, both the MIC and MBC levels of TP1 were found to be higher than that of LL-37 and PG1. On the other hand, the MIC and MBC values of B. pseudomallei for all three AMPs were observed higher than E. coli. In conclusion, TP1 exhibited B. pseudomallei inhibition, although not as potent as PG1 and LL-37.

\section{Time-kill kinetic assay of B. pseudomallei}

At $221 \mu \mathrm{M}$ of TP1, the growth inhibition of B. pseudomallei K96243 was observed within two hours after exposure compared to that of CAZ (8 hours) (Fig. 1). At $110 \mu \mathrm{M}$, TP1 managed to 


\section{Manuscript to be reviewed}

348 inhibit the growth of B. pseudomallei K96243 following eight hours of exposure compared to

349 the growth of the untreated bacteria at the same time point (approximately $9.0 \log \mathrm{CFU} / \mathrm{ml}$ ),

350 similar to CAZ. At $55 \mu \mathrm{M}$, there was a slight inhibition of the growth of $B$. pseudomallei

$351 \mathrm{~K} 96243(9.96 \log \mathrm{CFU} / \mathrm{ml})$ as compared to the untreated bacteria $(10.17 \log \mathrm{CFU} / \mathrm{ml})$ at 24

352 hours, albeit not significant. Overall, TP1 was able to inhibit B. pseudomallei K96243 growth

353 at a concentration above at $55 \mu \mathrm{M}$ and in a shorter duration as compared to CAZ.

354

355

Inhibition activity of AMPs against B. pseudomallei in biofilm state

B. pseudomallei K96423 in biofilm state was exposed to the 11 different AMPs (1mg/ml) using

MBEC assay (Fig 2). Of the AMPs tested, only TP1, 1018, and PG1 demonstrated significant inhibition (4.2 $\log$ CFU/biofilm, $7.2 \log$ CFU/biofilm, and $1.1 \log$ CFU/biofilm, respectively) compared to the untreated bacteria (7.8 log CFU/biofilm). CAZ and MRP demonstrated complete inhibition. At the same, using $1 \mathrm{mg} / \mathrm{ml}$ of TP1, LL-37, and PG1 (which was equivalent to $442 \mu \mathrm{M}, 222 \mu \mathrm{M}$, and $464 \mu \mathrm{M}$, respectively), the inhibition activity of TP1 was

3.5-log lower than PG1 but approximately 2.0-log higher than LL-37 compared to the untreated bacteria (7.8 $\log$ CFU/biofilm). There was no significant inhibition between LL-37-treated bacteria and the untreated bacteria. The inhibition activity of TP1 was higher that LL-37, but lower than CAZ, MRP, and PG1.

When B. pseudomallei K96243 in biofilm state was exposed to increasing concentrations of TP1 (from $55 \mu \mathrm{M}$ to $2649 \mu \mathrm{M}$; two-fold increase), the number of cells gradually decreased from $7.84 \log \mathrm{CFU} /$ biofilm to $3.6 \log \mathrm{CFU} /$ biofilm (Fig. 3). There was a significant decrease in the number of cells when exposed to all the TP1 concentrations as compared to the untreated cells $(0 \mu \mathrm{M})$. In addition, TP1 was observed to suppress the growth of the cells in biofilm state at concentrations above $442 \mu \mathrm{M}(\sim 4.00 \log \mathrm{CFU} /$ biofilm; $~ 2.0-\log \mathrm{CFU} / \mathrm{biofilm}$ reduction 
373 compared to the untreated) although MBEC was not achieved. There were significant growth

374 inhibitions observed when the bacteria were exposed to TP1 at $55 \mu \mathrm{M}$ and $100 \mu \mathrm{M}(1.0-\log$

375 reduction) as well as $221 \mu \mathrm{M}$ and $442 \mu \mathrm{M}$ (1.3- $\log$ reduction). In general, TP1 was able to

376 reduce the number of $B$. pseudomallei in biofilm state from concentrations above $55 \mu \mathrm{M}$.

\section{Scanning Electron Microscopy (SEM)}

The untreated B. pseudomallei cells, in basal RPMI medium, displayed a smooth and intact corrugated with dimples on the surface, and the appearance of blisters and bubbles were also observed on the membrane (Fig. 4, Panel B). Moreover, some of the cells were also observed to lose their original structure, leaving cell debris intermixed with the cell membranes that were blebbing. Similar observation was also seen with E. coli (Fig. 4, Panel C and Fig. 4, Panel D).

\section{Cytotoxicity of AMPs on mammalian cell lines}

387 As the concentration of TP1 increased (from $2.7 \mu \mathrm{M}$ to $110.4 \mu \mathrm{M}$ ), the percentage of viable cells for all three cell lines used were found to be decreased (from $92.0 \%$ to $15 \%$, respectively for A549, $94.1 \%$ to $8.3 \%$, respectively for HEPG2, and $85.1 \%$ to $50.1 \%$, respectively for AGS). Besides that, at $48.6 \mu \mathrm{M}$ and $110.4 \mu \mathrm{M}$ of TP1, there was a significant reduction of cell viability in all three cell lines compared to that of lower concentrations of TP1 (from $2.7 \mu \mathrm{M}$ to 22.3 $\mu \mathrm{M})$. Among the three cell lines tested, at $48.6 \mu \mathrm{M}$ and $110.4 \mu \mathrm{M}$, AGS showed a higher percentage of viability ( $80 \%$ and $50 \%$, respectively) compared to A549 (57\% and 15\%, respectively) and HEPG2 (57\% and $8 \%$, respectively). On the other hand, at lower concentrations of TP1 from $2.7 \mu \mathrm{M}$ to $22.3 \mu \mathrm{M}$, HEPG2 showed higher percentage of viability $(90.5 \% \pm 7.6 \%)$ compared to that of AGS $(90.0 \% \pm 8.4 \%)$ and A549 $(85.8 \% \pm 9.6 \%)$. When the 


\section{Manuscript to be reviewed}

398 of PG1), TP1 showed lesser cytotoxicity (15.0\% for A549, 8.3\% for HEPG2, and 50.1\% for

399 AGS) compared to that of PG1 (3.3\% for A549, 5.0\% for HEPG2, and 3.0\% for AGS) (Fig. 5).

400 Overall, HEPG2 cells demonstrated higher percentage of cell viability compared to the AGS at

401 the lower concentrations of TP1 $(2.7 \mu \mathrm{M}$ to $11.0 \mu \mathrm{M})$, albeit at a not significant level. However,

402 AGS demonstrated significantly higher percentage of cell viability $(\mathrm{P}<0.05)$ compared to

HEPG2 at the higher concentrations of TP1 $(48.6 \mu \mathrm{M}-110.4 \mu \mathrm{M})$. In general, TP1 has lower

404

cytotoxicity at concentrations between $2.7 \mu \mathrm{M}$ to $22.3 \mu \mathrm{M}$ where HEPG2 demonstrated more

405 tolerance to TP1.

406

407 At this stage, TP1 demonstrated inhibition activities on the tested B. pseudomallei strains comparable to LL-37 and PG1. SEM also revealed that TP1 was able to induce membrane blebbing, disrupting the membrane integrity and eventually leading to cell death. To date, the exact target on B. pseudomallei for TP1 binding has yet to be reported but there were existing reports of TP1 binding to the LPS (Kushibiki et al. 2014) and membrane (Hong et al. 2015) of E. coli as well as the minor groove of the DNA (Yonezawa et al. 1992). Therefore, in silico molecular docking was carried out to predict the binding targets of TP1 on B. pseudomallei.

Possible TP1 interactions with protein targets from in silico molecular docking study

Interaction of TP1 to the LPS of E. coli

417 TP1 was observed to interact with the LPS of $E$. coli with a binding affinity from ADV of -5.4 $418 \mathrm{kcal} / \mathrm{mol}$ and an IE of $-838.34 \mathrm{kcal} / \mathrm{mol}$ where the interaction was mostly contributed by electrostatic -810.79 kcal/mol compared to VDW (-27.55 kcal/mol; Table 3). The IE of TP1 was mostly contributed by residues LYS1 and ARG 15 (-121.19 kcal/mol and -239.74 $\mathrm{kcal} / \mathrm{mol}$, respectively) while the IE of LPS was contributed mostly by the PO4 residue ($356.16 \mathrm{kcal} / \mathrm{mol}$ ). Moreover, nine hydrogen bonds were formed between TP1 and the LPS of 
E. coli at TP1:LYS1:HT1 - LPS: FTT1010:O3, TP1:ARG15: HH11 - LPS: KDO1002:O1A,

424

425

426

427 TP1:ARG15: HH12 - LPS: PO42001:O1, TP1:ARG15: HH12 - LPS: PO42001:O2, TP1:ARG15: HH22 - LPS: GCN1001:O4, TP1:ARG15: HH22 - LPS: PO42001:O1, TP1:ARG17: HE - LPS: KDO1003:O7, TP1:ARG17: HE - LPS: KDO1003:O8, and TP1:ARG17: HH22 - LPS: KDO1003:O8, where the hydrogen bonds were formed mostly at the terminal ends of TP1 (Figure 6). However, there were no hydrophobic interactions observed between the TP1 and LPS. As such, the TP1-LPS docked complex was stabilized the intermolecular hydrogen bonds formed.

\section{Interaction of TP1 to Streptococcus pneumoniae protein structures}

Based on the molecular docking using ADV, TP1 interacted with all three $S$. pneumoniae proteins with a binding affinity of $-8.1 \mathrm{kcal} / \mathrm{mol}$ for autolysin, $-7.7 \mathrm{kcal} / \mathrm{mol}$ for pneumolysin, and $-7.3 \mathrm{kcal} / \mathrm{mol}$ for PspA (Table 4). This indicates that TP1 has a higher binding affinity to autolysin, followed by pneumolysin, and PspA. In addition, the number of hydrogen bonds formed between TP1 and the S. pneumoniae proteins demonstrated a similar trend to the binding affinity where the autolysin (with the highest binding affinity) formed 13 bonds with TP1, followed by pneumolysin (nine bonds) and PspA (eight bonds). However, based on the IE, TP1 demonstrated stronger interaction with PspA (-573.48 kcal/mol), followed by autolysin $(-444.14 \mathrm{kcal} / \mathrm{mol})$, and pneumolysin $(-135.59 \mathrm{kcal} / \mathrm{mol})$. Moreover, there were additional intermolecular interactions between TP1-penumolysin and TP1-PspA docked complexes but none was detected with TP1-autolysin docked complex. TP1- pneumolysin docked complex was observed to contain two pi-cation interactions between ARG9 of TP1 to TRP433 of pneumolysin. On the other hand, TP1-PspA docked complex demonstrated three types of additional interactions; one pi-pi interaction (TRP2 to TYR 541 of PspA), four pi-cation interactions (LYS1 to TRP 525 of PspA; three bonds from LYS1 to TRP518 molecules), and 
a pi-sigma interaction between LYS1 to TRP 518 of PspA. Based on the data obtained, among

449

450

451

452

453

454

455

456

457

458

459

460

461

462

463

464

465

466

467

468

469

470

471

472

the three S. pneumoniae proteins, TP1 was predicted to bind to autolysin at close proximity but was predicted to form the strongest interaction and the most stable docked complex with PspA.

\section{Interaction of TP1 on homology modelled B. pseudomallei protein structure}

Homology model of PspA B. pseudomallei (YDP model) was evaluated to ensure acceptable model quality (Supplementary 5). TP1 was observed to interact with the YDP model with a binding affinity of $-7.6 \mathrm{kcal} / \mathrm{mol}$ and an IE of $-822.80 \mathrm{kcal} / \mathrm{mol}$ where the interaction was mostly contributed by electrostatic IE $-770.63 \mathrm{kcal} / \mathrm{mol}$ compared to VDW IE $(-52.17$ $\mathrm{kcal} / \mathrm{mol}$; Table 5). The binding affinity and the IE indicated that TP1 will bind to the YDP model in close proximity with a strong intermolecular interaction. The IE of TP1 was mostly contributed by residues LYS1, ARG 14, and ARG 15 (-158.78 kcal/mol, -160.54 kcal/mol, and $-124.82 \mathrm{kcal} / \mathrm{mol}$, respectively) while the IE of YDP was contributed mostly by ASP 1220 ($209.81 \mathrm{kcal} / \mathrm{mol})$ and ASP 1169 (-190.00 kcal/mol). Moreover, nine hydrogen bonds were observed between TP1 and YDP model at TP1:LYS1: HZ2 to YDP: THR1113: O, TP1:CYS12:HN to YDP: SER1185: OG, TP1:ARG14: HE to YDP: ASP1169:OD1, TP1:ARG14: HE to YDP: ASP1169:OD2, TP1:ARG14: HH22 to YDP: ASP1169:OD1, TP1:ARG17: HH22 to YDP: ASP1120:OD2, YDP: SER1155: HG to TP1:CYS16: O, YDP: ARG1157:HH12 - TP1:CYS12: O, and YDP: TYR1166: HH to TP1:CYS12: O (Fig 7). However, there were no hydrophobic interactions observed between the TP1 and YDP. In general, the TP1-YDP model was stabilized by the intermolecular hydrogen bonds formed.

Along with the common binding protein targets for peptide and inhibitors, the PDB database search was performed and the available B. pseudomallei PDB structures (Supplementary 6) were subjected to molecular docking to predict the possible interactions with TP1 
473 (Supplementary 7). Of the 26 B. pseudomallei proteins retrieved PDB (including stress

474 proteins, secretion needle proteins, and penicillin binding pump) binding affinities from -5.7

$475 \mathrm{kcal} / \mathrm{mol}$ to $-11.2 \mathrm{kcal} / \mathrm{mol}$ were observed. Besides that, seven proteins with the interaction of

476 amino acids in target receptor from peptide less than -100 kcal/mol (with CHARMm force

477 field) were then further analysed to identify additional hydrogen bonds and intermolecular pi-

478 interactions (Supplementary 8). TP1 demonstrated the most negative interaction energy with

479 the cell inhibiting factor (PDB ID: 3GQM; $-230.75 \mathrm{kcal} / \mathrm{mol}$ ) with a binding affinity of -8.5

$480 \mathrm{kcal} / \mathrm{mol}$, six hydrogen bonds, and two cation-pi interactions. Based on the total interaction

481 energy of all the 26 of the TP1- B. pseudomallei docked complex structures, the key amino

482 acid residues of TP1 that displayed strong interaction energy with B. pseudomallei structures were from the terminal amino acids of peptides; LYS1, ARG5, CYS7, TYR8, ARG9, ILE11,

ARG14, CYS16, and ARG17 (Supplementary 7).

\section{Discussion}

Treatment of melioidosis involves long courses of antibiotics which often lead to resistance (Dance 2014b). Therefore, researchers are aiming for alternative antimicrobial agents such as AMPs in order to contain the situation. AMPs have made a big impact in antimicrobial research, to diminish the inefficacy of antimicrobial therapy in immunocompromised hosts and also ongoing emergence of resistance to conventional antibiotics worldwide (Giuliani et al. 2007). Among the AMPs which were reported to demonstrate potential to inhibit $B$. pseudomallei include LL-37 (Kanthawong et al. 2012), PG1 (Sim et al. 2011), bovine lactoferrin (Puknun et al. 2013), phospholipase A2 (Samy et al. 2015), and SMAP-29 (Blower et al. 2015). However, there are more potential AMPs that are yet to be tested against $B$. pseudomallei. In that instance, TP 1, a 17-residue AMP arranged in two anti-parallel $\beta$-sheets 


\section{Manuscript to be reviewed}

498 shoe crab, Tachypleus tridentatus (Nakamura et al. 1988) was shown to exert broad-spectrum

499 antimicrobial activity against a wide range of Gram-negative (i.e. E. coli, and S. typhimurium)

500 and Gram-positive bacteria (i.e. Staphylococcus aureus) (Nakamura et al. 1988; Ohta et al.

501 1992). To date, the inhibition activity of TP1 on B. pseudomallei is yet to be reported. As such,

502 our studies focus to understand the mode of action of AMPs, specifically the TP1 and to

503 identify potential interaction targets on B. pseudomallei.

504

505 In the preliminary screening, we observed that the activity of the AMPs was not affected by

506 the antimicrobial susceptibility of the B. pseudomallei isolates. A similar observation was

507 reported by Mataraci \& Dosler (2012) where their tested strain, methicillin-resistant S. aureus

508 (MRSA) ATCC 43300 were susceptible to AMPs indolicidin and cecropin (1-7)-melittin A (2-

509 9) amide (CAMA).

510

511 Advancing from the preliminary study, the MIC and MBC values of TP1 were determined to 512 be higher than LL-37 and PG1. These high inhibition values of TP1 towards B. pseudomallei may be due to its non-specific binding where more TP1 molecules were required to bind to the B. pseudomallei isolates in order to exhibit the inhibition activity. TP1 may be prone to aggregation at inhibitory concentrations where some experimental evidence may assist in reducing the inhibition values of the AMP. The higher B. pseudomallei inhibition values may 517 result from the bacteria lowering the membrane surface net charge or altering the hydrophobicity (Peschel 2002; Poole 2002). In addition, the inhibition values of LL-37 and PG1 in our study were higher that the findings of Kanthawong et al. (2012) and Sim et al. 


\section{Manuscript to be reviewed}

52337 and PG1, there is always a possibility that the strains used for this study has adapted to the

524 laboratory environment after many passages, thus displaying properties not observed with the

525 same strain used in other laboratories. However, the antimicrobial activity trend in our study

526 was similar and the values obtained from each replicate were the same. In our study, E. coli

527 ATCC 25922 was used as a control microorganism since it was reported susceptible to LL-37

528 (Baranska-Rybak et al. 2006), PG1(Aumelas et al. 1996), and TP1 (Hong et al. 2015).

529

530 In the time-kill study, TP1 inhibited B. pseudomallei K96243 within two hours of exposure 531 compared to that of conventional antibiotics, CAZ. Most importantly, TP1 did not enhance $B$. 532 pseudomallei activity. Similar observation was also reported with LL-37 by Kanthawong et al.

533 (2012), where LL-37 inhibited B. pseudomallei 1026b, within two hours of post exposure.

534 These observations also support the fact that AMPs exhibit bactericidal effect at a shorter 535 duration compared to conventional antibiotics, which gives the microorganism lesser chances 536 to develop resistance (Hancock 2001; Rodriguez-Rojas et al. 2014).

537

538 During the biofilm state of the growth, the maximum inhibition of B. pseudomallei cells in 539 biofilm state $(442 \mu \mathrm{M})$ was higher that the MBC of the planktonic cells (221 $\mu \mathrm{M})$. Similarly, 540 Anutrakunchai et al. (2015) have also reported that the CAZ susceptibilities of B. pseudomallei biofilm were much higher than those of planktonic cells. Moreover, the protective extracellular

542 polymeric substance encasing B. pseudomallei in biofilm state prevents uptake by phagocytic 543 cells (Taweechaisupapong et al. 2005) and also causes the bacteria to be refractory to 544 antimicrobial action (Di Luca et al. 2014). Due to the non-specific binding of AMPs to the components of the EPS, there was insufficient AMPs molecules to exhibit inhibition effect on the bacterial cells. In a study by Chan et al. (2004), Pseudomonas aeruginosa in biofilm form secrete alginate which induces $\alpha$-helical conformation on modified magainin 2 and cecropin 


\section{Manuscript to be reviewed}

548 P1, thus diminishing its antimicrobial activity. Based on our data, there is always a possibility

549 of B. pseudomallei AMP resistance in biofilm state but TP1 has shown reproducible results

550 across replicates, comparable to that of PG1 and possibly even more consistent than LL-37.

551 Moreover, both TP1 and PG1 were observed to inhibit B. pseudomallei in planktonic and

552 biofilm state. However, LL-37 only exerted its antimicrobial activity on planktonic $B$.

553 pseudomallei cells. Our observation contradicted with the study conducted by Kanthawong et

554 al. (2012), where they reported anti- B. pseudomallei biofilm activities with $100 \mu \mathrm{M}$ of LL-37

555 and biofilm inhibition activities with $936 \mu \mathrm{M}$ of CAZ. This could be due to the strains variation,

556 where strains resistant to CAZ but susceptible to LL-37 were used, as compared to the $B$.

557 pseudomallei K96243 used in our study (susceptible to CAZ and tolerated LL-37) in biofilm

558 state. In addition, CAZ and MRP appeared most active against B. pseudomallei K96243 in

559 biofilm state as the isolate was already susceptible to both the antibiotics from the antibiotic

560 susceptibility profile (Supplementary 2). Where serial dilution and plating on NA was

561 involved, the $\mathrm{CFU} / \mathrm{ml}$ or CFU/biofilm can only be detected if there were any bacteria colonies

562 growing on the agar surface. The graph in Fig 3 plateaus at approximately $4 \log$ CFU/biofilm was an example where the limits of detection may apply. Therefore, in these studies, although countable colonies are present but below the countable range (standard counting range are between 25 to 250 colonies), they were still counted and reported.

567 Overall, in the MIC and MBC method used in our study slightly differs from the CLSI methods 568 for measuring antibiotic susceptibility (Cockerill et al. 2012). RPMI 1640 was used as it is able to sustain bacterial growth although not as nutrient-rich compared to LB or Muller Hinton broth (MHB). Schwab et al. (1999) used RPMI 1640 (with 20 mM HEPES and without sodium bicarbonate) to study the inhibition activities of AMPs D2A21 and D4E1 on S. aureus ATCC 29213 and P. aeruginosa ATCC 27853. The highest AMPs activity in this media was observed, 
573 while it supported the growth of the bacteria, as compared to trypticase soy broth and nutrient

574 broth. We speculate that the extracts in LB (yeast) and MHB (beef) do not have a consistent

575 composition may contain components which may lead to the non-specific bindings of the

576 AMPs and thus diminishing the AMPs activity.

577

578 Our SEM analysis revealed that TP1 acts on the bacterial membrane, suggesting that due to the loss of membrane integrity, the bacteria fail to contain their cytoplasmic components and thus, causing them to lyse. The observations with E. coli were similar to the findings of Hartmann et al. (2010) with $\beta$ - hairpin antimicrobial peptides. To the best of our knowledge, this is the first report on the effect of TP1 on B. pseudomallei. Furthermore, also using E. coli ATCC 25922, Hong et al. (2015) also observed that TP1 damaged the entire cell, including the structure of the cell wall and membrane. Pore formation and partial disruption of the cell wall and cytoplasmic membrane was also observed, resulting in the outflow of cell contents and the complete collapse of some cells.

The AMPs in this study were synthesized as acetate salts which do not pose any known effects as the presence of trifluoroacetic acid (commonly used in peptide synthesis) is cytotoxic and undesirable in preclinical and clinical studies (LifeTein 2015). At the moment, TP1 is not suitable for therapy due to its in vitro cytotoxicity unless certain modification was done (i.e. to reduce non-specific binding). As limited data is available to modify the AMP; we believe that our findings will contribute to the existing literature so that this AMP can be modified to specifically target either bacteria cells or cancer cells. Although LL-37 was reported to possess anti-B. pseudomallei properties (Kanthawong et al. 2012), it has been reported to be cytotoxic to both A549 (Aarbiou et al. 2006), and AGS (Wu et al. 2010) and was not included in our study. On the other hand, PG1, was reported cytotoxic against Hep G2 (Niu et al. 2015) but the 
effect was yet to be reported on A549 and AGS. One of the disadvantages of AMPs is they are cytotoxic will require certain modification to nullify the effect.

600

601 In the in silico study, we have successfully docked TP1 on the LPS of E. coli with similar 602 parameters as stated in Kushibiki et al. (2014) using ADV instead of AutoDock 4.2 where ADV was programmed with significant improvement the average accuracy of the binding mode predictions compared to AutoDock 4.2 (Trott \& Olson 2010). Our findings were similar to Kushibiki et al. (2014) where we observe that ARG17 residues of TP1 were involved in the binding to LPS while the PO4 groups of the LPS were involved in the binding to TP1(hence the hydrogen bonds between both molecules). Moreover, we also observed that the lack of noncovalent interactions (pi-interactions), maybe due to the lack of benzene and other aromatic residues in the LPS molecule to contribute to the interaction. The slight differences in the binding residues of TP1 to LPS maybe due to the differences in the algorithm of both docking software (Trott \& Olson 2010). However, most of binding residues in the LPS of E. coli in the docking study by Kushibiki et al. (2014) were reproducible. On the side note, we are aware of the variation of the O-antigen (connected to the LPS in the outer membrane) among Gramnegative bacteria. However, the basic structure of the LPS comprised of repeated oligosaccharide units, where each unit was made up of common sugars such as hexoses and hexosamines (Reyes et al. 2012). Therefore, interaction of TP1 with E. coli may be used as a basis for the prediction of the TP1 interaction with B. pseudomallei. At the moment, the exact role of the YDP of B. pseudomallei has yet to be reported. However, from the verification of the homology modelled B. pseudomallei protein based on PspA, and the membrane blebbing observed in the SEM analysis., we hypothesize that the YDP may contribute to a surface protein on B. pseudomallei where it interacted with TP1 molecules. 
622 Taken together; our docking results show negative binding energies indicated favourable

623

624

625

626

627

628

629

630

631

632

633

634

635

636

637

638

639

640

641

642

643

644

645

646

bindings of TP1 with all three receptors, LPS of E. coli and the homologically modelled YDP.

Although the binding affinity of TP1 to the LPS was not as strong as that of autolysin, pneumolysin, and PspA, the IE of TP1-LPS complex was the most negative, indicating a stronger interaction as compared to PspA autolysin, and pneumolysin. Moreover, the binding affinity and IE of TP1 to the autolysin, pneumolysin, and PspA may indicate that the binding sites for the respective molecules were the common binding sites for $S$. pneumoniae inhibitors.

The binding affinity and the IE of YDP model was higher than that of the template molecule PspA indicating that TP1 has a stronger interaction with the YDP model. Moreover, the IE of YDP model was observed to be similar than that of LPS of E. coli, which hinted that TP1 has similar interaction strength for both of the molecules. However, there were no pi-interactions in the TP1-YDP complex as compared to the TP1-PspA complex. This may indicate that TP1PspA complex was more stable compared to TP1-YDP complex but TP1 has a stronger interaction to YDP model compared to PspA complex.

Based on our docking study with B. pseudomallei PDB structures, TP1 has the highest probability of binding to B. pseudomallei cycle inhibiting factor (PDB ID: 3GQM) when both molecules are in close proximity since the total interaction energy was the most negative of all the docked proteins. The binding of TP1 to the cycle inhibiting factor of B. pseudomalle $i$ is expected cause the down regulation of this protein during the interaction. Similar down regulation of the universal stress protein was reported by Aanandhi et al. (2014) on a study of the interaction natural polyphenols with Mycobacterium tuberculosis. Moreover, the binding of AMPs to proteins in general are based on a few key residues on the AMPs themselves. These are often termed as "hot spot" residues (Clackson \& Wells 1995; London et al. 2010)). In our 
647 study, we have identified key residues in TP1 which react with all the $B$. pseudomallei proteins,

648 summarized and calculated based on their critical contribution to the total binding energy. As

649 such, we propose that any modification done on TP1 specifically for B. pseudomallei should

650 avoid tempering with those key residues.

651

652 Conclusions

653 Herein, we have selected commercially available peptide, TP1 as the potential AMP against $B$.

654 pseudomallei. Based on the above findings, TP1 has shown great prospect as an anti-B.

655 pseudomallei agent where its efficacy is comparable to that of LL-37 and PG1. The in silico

656 data suggest that TP1 has a strong interaction not only to B. pseudomallei proteins but also

657 other Gram-negative and Gram-positive bacteria as well. Besides that, we have demonstrated

658 TP1's efficacy on B. pseudomallei isolated in both planktonic and biofilm form with the

659 additional supporting data from the in silico study. Possible TP1 interactions with the common

660 peptide or inhibitor binding targets for LPS of E. coli, as well as autolysin, pneumolysin, and

661 PspA of S. pneumoniae from in silico molecular docking study were also identified. Further

662 modifications of TP1 can be done to enhance its specificity to B. pseudomallei and to reduce

663 its cytotoxicity. With the current technology, we also propose further experiments such as

664 coarse-grain molecular dynamics to simulate the interaction between TP1 and B.pseudomallei

665 outer membrane (Hall et al. 2011). Besides that, TP1 can also be tagged with a fluorescent

666 compound to visualize TP1 movement in live B. pseudomallei cells (Gee et al. 2013).

667 Proteomic analysis and embedding of TP1 on resins to carry out affinity chromatography on

668 B. pseudomallei whole bacteria, coupled with liquid chromatography-mass spectrometry will

669 enable in-depth understanding on the effect of TP1 on B. pseudomallei protein structures

670 (Casey et al. 2008; Ortiz-Martin et al. 2015)

671 


\section{Manuscript to be reviewed}

\section{Acknowledgements}

673 We would also like to thank Dr. Ding Jeak Ling and Dr. Roger W Beuerman (National 674 University of Singapore), and Dr. Bob Hancock (University of British Columbia) for providing 675 the AMPs for this study.

676

677 Figure Legends

678 Fig. 1. Time killing curve of TP1 compared to that of CAZ for B. pseudomallei K96243.

679

680

681

682

683

684

685

686

687

688

689

690

691

692

693

694

695

B. pseudomallei K96243 was exposed to TP1 (55 $\mu \mathrm{M}, 110 \mu \mathrm{M}$, and $221 \mu \mathrm{M})$ and CAZ (54 $\mu \mathrm{M})$. Data was presented as mean and standard deviation of three independent replicates, analyzed with one-way Anova followed by Dunnett's test to determine the significance relative to the untreated bacteria $(\mathrm{P}<0.05)$.

Fig. 2. Number of surviving B. pseudomallei K96243 in biofilm state post 24-hour post antimicrobial peptides exposure.

The concentration of antimicrobial agents used were $1 \mathrm{mg} / \mathrm{ml}$. TP1, 1018, PG1, CAZ and MRP showed significant reduction compared to the untreated. These experiments were conducted in three independent replicates. The error bars indicate the standard deviation. One-way Anova followed by Dunnett's test was performed to determine the significance relative to the untreated bacteria $(\mathrm{P}<0.05)$, indicated using *.

Fig. 3. Number of surviving B. pseudomallei K96243 in a biofilm state 24-hour postexposure to TP 1

B. pseudomallei K96243 was exposed to different concentrations of TP1 (55 $\mu \mathrm{M}$ to $2649 \mu \mathrm{M}$, with twofold increase). These experiments were performed in three independent replicates where the error bars indicate the standard deviation. Data was analyzed with one-way Anova 


\section{Manuscript to be reviewed}

696 followed by Dunnett's test to determine the significance relative to the untreated bacteria $(\mathrm{P}<$

697 0.05), indicated by *.

698

699

Fig.4. Scanning electron microscopy (SEM) observation of B. pseudomallei K96243 pre-

700

exposure (Panel A) and post-exposure (Panel B) of $62 \mu \mathrm{M}$ TP1, and E. coli ATCC 29522

701

pre- exposure (Panel C) and post- exposure (Panel D) of $22 \mu \mathrm{M}$ of TP1.

702

703

704

705

706

707

708

709

710

711

712

713

714

715

716

717

718

719

Fig. 5. Percentage of viability of A549, HEPG2 and AGS cell lines post-exposure to TP1, PG1, MRP and CAZ.

The cell lines were exposed to TP1 $(0 \mu \mathrm{M}, 2.7 \mu \mathrm{M}, 5.5 \mu \mathrm{M}, 11.0 \mu \mathrm{M}, 22.3 \mu \mathrm{M}, 48.6 \mu \mathrm{M}, 110.4$ $\mu \mathrm{M}), \mathrm{PG} 1(115 \mu \mathrm{M}), \mathrm{MRP}(26 \mu \mathrm{M})$, and CAZ $(54 \mu \mathrm{M})$. These experiments were conducted in three independent replicates where the error bars indicate the standard deviation. Data was analysed with one-way Anova followed by Dunnett's test to determine the significance relative to the untreated bacteria $(\mathrm{P}<0.05$; indicated by $*)$.

Fig. 6. Graphical representation of LPS of $E$. coli and TP1 interaction.

Superimposed TP1 was coloured blue while the LPS molecule was coloured grey (Panel A).

The binding amino acids and hydrogen bonds were indicated by green dashes (Panel B). Five hydrogen bonds were formed, mostly at the terminal ends of TP1:ARG15: HH22 - A: PA11000:O4, TP1:ARG17: HE - A: KDO1003:O7, TP1:ARG17: HE - A: KDO1003:O8, TP1:ARG17: HH22 - A: KDO1003:O8, and A: GLC1007:H6 - TP1:ARG14: O

\section{Fig. 7. Graphical representation of YDP model and TP1 interaction.}




\section{PeerJ}

\section{Manuscript to be reviewed}

720 Superimposed TP1 was coloured blue while YDP model was coloured yellow (Panel A). The

721 binding amino acids and hydrogen bonds were indicated with green dashes (Panel B).

722 Nine hydrogen bonds were observed between TP1 and YDP: TP1:LYS1to YDP: THR1113,

723 TP1:CYS12 to YDP: SER1185, TP1:ARG14 to YDP: ASP1169, TP1:ARG14 to YDP:

724 ASP1169, TP1:ARG14 to YDP: ASP1169, TP1:ARG17 to YDP: ASP1120, YDP: SER1155

725 to TP1:CYS16, YDP: ARG1157 to TP1:CYS12, and YDP: TYR1166 to TP1:CYS1.

726

727 


\section{Manuscript to be reviewed}

\section{References}

729

730

Aanandhi MV, Bhattacherjee D, George PS, and Ray A. 2014. Natural polyphenols down-regulate universal stress protein in Mycobacterium tuberculosis: An in-silico approach. J Adv Pharm Technol Res 5:171-178. 10.4103/2231-4040.143036

Aarbiou J, Tjabringa GS, Verhoosel RM, Ninaber DK, White SR, Peltenburg LT, Rabe KF, and Hiemstra PS. 2006. Mechanisms of cell death induced by the neutrophil antimicrobial peptides alphadefensins and LL-37. Inflamm Res 55:119-127. 10.1007/s00011-005-0062-9

Al-Maleki AR, Mariappan V, Vellasamy KM, Shankar EM, Tay ST, and Vadivelu J. 2014. Enhanced intracellular survival and epithelial cell adherence abilities of Burkholderia pseudomallei morphotypes are dependent on differential expression of virulence-associated proteins during mid-logarithmic growth phase. Journal of Proteomics 106:205-220. DOI 10.1016/j.jprot.2014.04.005

Al-Sohaibani S, and Murugan K. 2012. Anti-biofilm activity of Salvadora persica on cariogenic isolates of Streptococcus mutans: in vitro and molecular docking studies. Biofouling 28:29-38. 10.1080/08927014.2011.647308

Alloing G, Trombe MC, and Claverys JP. 1990. The ami locus of the gram-positive bacterium Streptococcus pneumoniae is similar to binding protein-dependent transport operons of gram-negative bacteria. Mol Microbiol 4:633-644.

Alves MJ, Ferreira IC, Froufe HJ, Abreu RM, Martins A, and Pintado M. 2013. Antimicrobial activity of phenolic compounds identified in wild mushrooms, SAR analysis and docking studies. J Appl Microbiol 115:346-357. 10.1111/jam.12196

Anutrakunchai C, Sermswan RW, Wongratanacheewin S, Puknun A, and Taweechaisupapong S. 2015. Drug susceptibility and biofilm formation of Burkholderia pseudomallei in nutrient-limited condition. Trop Biomed 32:300-309.

Aumelas A, Mangoni M, Roumestand C, Chiche L, Despaux E, Grassy G, Calas B, and Chavanieu A. 1996. Synthesis and solution structure of the antimicrobial peptide protegrin-1. Eur J Biochem 237:575-583.

Baranska-Rybak W, Sonesson A, Nowicki R, and Schmidtchen A. 2006. Glycosaminoglycans inhibit the antibacterial activity of LL-37 in biological fluids. J Antimicrob Chemother 57:260-265. 10.1093/jac/dki460

Batoni G, Maisetta G, Brancatisano FL, Esin S, and Campa M. 2011. Use of antimicrobial peptides against microbial biofilms: advantages and limits. Curr Med Chem 18:256-279.

Beveridge TJ. 1999. Structures of Gram-Negative Cell Walls and Their Derived Membrane Vesicles. J Bacteriol 181:4725-4733.

Blower RJ, Barksdale SM, and van Hoek ML. 2015. Snake Cathelicidin NA-CATH and Smaller Helical Antimicrobial Peptides Are Effective against Burkholderia thailandensis. PLoS Negl Trop Dis 9:e0003862. 10.1371/journal.pntd.0003862

Casey JL, Coley AM, and Foley M. 2008. Phage display of peptides in ligand selection for use in affinity chromatography. Methods Mol Biol 421:111-124.

Chan C, Burrows LL, and Deber CM. 2004. Helix induction in antimicrobial peptides by alginate in biofilms. J Biol Chem 279:38749-38754. 10.1074/jbc.M406044200

Cheng AC, and Currie BJ. 2005. Melioidosis: epidemiology, pathophysiology, and management. Clin Microbiol Rev 18:383-416. 10.1128/CMR.18.2.383-416.2005

Clackson T, and Wells JA. 1995. A hot spot of binding energy in a hormone-receptor interface. Science 267:383-386.

Cockerill FR, Wikler MA, Alder J, Dudley MN, Eliopoulos GR, Ferraro MJ, Hardy DJ, Hecht DW, Hindler JA, Patel JB, Powell M, Swenson JM, Thomson RB, Traczewski MM, Turnidge J, Weinstein MP, and Zimmer BL. 2012. Methods for Dilution Antimicrobial Susceptibility Tests for Bacteria That Grow Aerobically; Approved Standard. Pennsylvania, USA: Clinical and Laboratory Standards Institute 


\section{Manuscript to be reviewed}

778 Colovos C, and Yeates TO. 1993. Verification of protein structures: patterns of nonbonded atomic interactions. Protein Sci 2:1511-1519. 10.1002/pro.5560020916

Cross JB, Thompson DC, Rai BK, Baber JC, Fan KY, Hu Y, and Humblet C. 2009. Comparison of several molecular docking programs: pose prediction and virtual screening accuracy. J Chem Inf Model 49:1455-1474. 10.1021/ci900056c

Dance D. 2014a. Treatment and prophylaxis of melioidosis. Int J Antimicrob Agents 43:310-318. 10.1016/j.ijantimicag.2014.01.005

Dance D. 2014b. Treatment and prophylaxis of melioidosis. Int J Antimicrob Agents 43:310-318. 10.1016/j.ijantimicag.2014.01.005

Di Luca M, Maccari G, and Nifosi R. 2014. Treatment of microbial biofilms in the post-antibiotic era: prophylactic and therapeutic use of antimicrobial peptides and their design by bioinformatics tools. Pathog Dis 70:257-270. 10.1111/2049-632X.12151

Fernandez-Recio J, Walas F, Federici L, Venkatesh Pratap J, Bavro VN, Miguel RN, Mizuguchi K, and Luisi B. 2004. A model of a transmembrane drug-efflux pump from Gram-negative bacteria. FEBS Lett 578:5-9. 10.1016/j.febslet.2004.10.097

Galdiero S, Falanga A, Cantisani M, Tarallo R, Della Pepa ME, D'Oriano V, and Galdiero M. 2012. Microbe-host interactions: structure and role of Gram-negative bacterial porins. Curr Protein Pept Sci 13:843-854.

Gee ML, Burton M, Grevis-James A, Hossain MA, McArthur S, Palombo EA, Wade JD, and Clayton AH. 2013. Imaging the action of antimicrobial peptides on living bacterial cells. Sci Rep 3:1557. 10.1038/srep01557

Giuliani A, Pirri G, and Nicoletto SF. 2007. Antimicrobial peptides: an overview of a promising class of therapeutics. Central European Journal of Biology 2:1-33. DOI 10.2478/s11535-007-0010-5

Gupta S, Kapoor P, Chaudhary K, Gautam A, Kumar R, Open Source Drug Discovery C, and Raghava GP. 2013. In silico approach for predicting toxicity of peptides and proteins. PLoS One 8:e73957. 10.1371/journal.pone.0073957

Hall BA, Chetwynd AP, and Sansom MS. 2011. Exploring peptide-membrane interactions with coarsegrained MD simulations. Biophys J 100:1940-1948. 10.1016/j.bpj.2011.02.041

Hancock RE. 2001. Cationic peptides: effectors in innate immunity and novel antimicrobials. Lancet Infect Dis 1:156-164. 10.1016/S1473-3099(01)00092-5

Hancock REW. 1999. Hancock Laboratory Methods. Available at http://cmdr.ubc.ca/bobh/methods/MODIFIEDMIC.html.

Hansen A, Schafer I, Knappe D, Seibel P, and Hoffmann R. 2012. Intracellular toxicity of proline-rich antimicrobial peptides shuttled into mammalian cells by the cell-penetrating peptide penetratin. Antimicrob Agents Chemother 56:5194-5201. 10.1128/aac.00585-12

Hartmann M, Berditsch M, Hawecker J, Ardakani MF, Gerthsen D, and Ulrich AS. 2010. Damage of the bacterial cell envelope by antimicrobial peptides gramicidin $S$ and PGLa as revealed by transmission and scanning electron microscopy. Antimicrob Agents Chemother 54:31323142. 10.1128/AAC.00124-10

Holden MT, Titball RW, Peacock SJ, Cerdeno-Tarraga AM, Atkins T, Crossman LC, Pitt T, Churcher C, Mungall K, Bentley SD, Sebaihia M, Thomson NR, Bason N, Beacham IR, Brooks K, Brown KA, Brown NF, Challis GL, Cherevach I, Chillingworth T, Cronin A, Crossett B, Davis P, DeShazer D, Feltwell T, Fraser A, Hance Z, Hauser H, Holroyd S, Jagels K, Keith KE, Maddison M, Moule S, Price C, Quail MA, Rabbinowitsch E, Rutherford K, Sanders M, Simmonds M, Songsivilai S, Stevens K, Tumapa S, Vesaratchavest M, Whitehead S, Yeats C, Barrell BG, Oyston PC, and Parkhill J. 2004. Genomic plasticity of the causative agent of melioidosis, Burkholderia pseudomallei. Proc Natl Acad Sci U S A 101:14240-14245. 10.1073/pnas.0403302101

Hong J, Guan W, Jin G, Zhao H, Jiang X, and Dai J. 2015. Mechanism of tachyplesin I injury to bacterial membranes and intracellular enzymes, determined by laser confocal scanning microscopy and flow cytometry. Microbiol Res 170:69-77. 10.1016/j.micres.2014.08.012 


\section{Manuscript to be reviewed}

Imura Y, Nishida M, Ogawa Y, Takakura Y, and Matsuzaki K. 2007. Action mechanism of tachyplesin I and effects of PEGylation. Biochim Biophys Acta 1768:1160-1169. 10.1016/j.bbamem.2007.01.005

Kanthawong S, Bolscher JG, Veerman EC, van Marle J, de Soet HJ, Nazmi K, Wongratanacheewin S, and Taweechaisupapong S. 2012. Antimicrobial and antibiofilm activity of LL-37 and its truncated variants against Burkholderia pseudomallei. Int J Antimicrob Agents 39:39-44. 10.1016/j.ijantimicag.2011.09.010

Kapetanovic IM. 2008. Computer-aided drug discovery and development (CADDD): in silico-chemicobiological approach. Chem Biol Interact 171:165-176. 10.1016/j.cbi.2006.12.006

Kitchen DB, Decornez H, Furr JR, and Bajorath J. 2004. Docking and scoring in virtual screening for drug discovery: methods and applications. Nat Rev Drug Discov 3:935-949. 10.1038/nrd1549

Kushibiki T, Kamiya M, Aizawa T, Kumaki Y, Kikukawa T, Mizuguchi M, Demura M, Kawabata S, and Kawano K. 2014. Interaction between tachyplesin I, an antimicrobial peptide derived from horseshoe crab, and lipopolysaccharide. Biochim Biophys Acta 1844:527-534. 10.1016/j.bbapap.2013.12.017

Laskowski RA, MacArthur MW, Moss DS, and Thornton JM. 1993. PROCHECK: a program to check the stereochemical quality of protein structures. Journal of Applied Crystallography 26:283-291. doi:10.1107/S0021889892009944

Le CF, Yusof MY, Hassan MA, Lee VS, Isa DM, and Sekaran SD. 2015. In vivo efficacy and molecular docking of designed peptide that exhibits potent antipneumococcal activity and synergises in combination with penicillin. Sci Rep 5:11886. 10.1038/srep11886

Lengauer T, and Rarey M. 1996. Computational methods for biomolecular docking. Curr Opin Struct Biol 6:402-406.

LifeTein. 2015. TFA removal service: switch to acetate or $\mathrm{HCl}$ salt form of peptide. Available at http://www.lifetein.com/TFA Removal Peptide Synthesis Services.html.

London N, Movshovitz-Attias D, and Schueler-Furman O. 2010. The structural basis of peptideprotein binding strategies. Structure 18:188-199. 10.1016/j.str.2009.11.012

Luthy R, Bowie JU, and Eisenberg D. 1992. Assessment of protein models with three-dimensional profiles. Nature 356:83-85. 10.1038/356083a0

Mataraci E, and Dosler S. 2012. In vitro activities of antibiotics and antimicrobial cationic peptides alone and in combination against methicillin-resistant Staphylococcus aureus biofilms. Antimicrob Agents Chemother 56:6366-6371. 10.1128/AAC.01180-12

Momany FA, and Rone R. 1992. Validation of the general purpose QUANTA 3.2/CHARMm force field. J Comput Chem 13:888-900. 10.1002/jcc.540130714

Nakamura T, Furunaka H, Miyata T, Tokunaga F, Muta T, Iwanaga S, Niwa M, Takao T, and Shimonishi Y. 1988. Tachyplesin, a class of antimicrobial peptide from the hemocytes of the horseshoe crab (Tachypleus tridentatus). Isolation and chemical structure. J Biol Chem 263:16709-16713.

Niu M, Chai S, You X, Wang W, Qin C, Gong Q, Zhang T, and Wan P. 2015. Expression of porcine protegrin-1 in Pichia pastoris and its anticancer activity in vitro. Exp Ther Med 9:1075-1079. 10.3892/etm.2015.2202

Ohta M, Ito H, Masuda K, Tanaka S, Arakawa Y, Wacharotayankun R, and Kato N. 1992. Mechanisms of antibacterial action of tachyplesins and polyphemusins, a group of antimicrobial peptides isolated from horseshoe crab hemocytes. Antimicrob Agents Chemother 36:1460-1465.

Ortiz-Martin L, Benavente F, Medina-Casanellas S, Gimenez E, and Sanz-Nebot V. 2015. Study of immobilized metal affinity chromatography sorbents for the analysis of peptides by on-line solid-phase extraction capillary electrophoresis-mass spectrometry. Electrophoresis 36:962970. 10.1002/elps.201400374

Peschel A. 2002. How do bacteria resist human antimicrobial peptides? Trends Microbiol 10:179-186. http://dx.doi.org/10.1016/S0966-842X(02)02333-8 
Poole K. 2002. Mechanisms of bacterial biocide and antibiotic resistance. Symp Ser Soc Appl Microbiol:55S-64S.

Puknun A, Bolscher JG, Nazmi K, Veerman EC, Tungpradabkul S, Wongratanacheewin S, Kanthawong $\mathrm{S}$, and Taweechaisupapong S. 2013. A heterodimer comprised of two bovine lactoferrin antimicrobial peptides exhibits powerful bactericidal activity against Burkholderia pseudomallei. World J Microbiol Biotechnol 29:1217-1224. 10.1007/s11274-013-1284-6

Puthucheary SD. 2009. Melioidosis in Malaysia. Med J Malaysia 64:266-274.

Reyes RE, González C, Jiménez R, Herrera MO, and Andrade AA. 2012. Mechanisms of O-Antigen Structural Variation of Bacterial Lipopolysaccharide (LPS), The Complex World of Polysaccharides. In: Karunaratne DN, ed.

Rodriguez-Rojas A, Makarova O, and Rolff J. 2014. Antimicrobials, stress and mutagenesis. PLoS Pathog 10:e1004445. 10.1371/journal.ppat.1004445

Rotem S, and Mor A. 2009. Antimicrobial peptide mimics for improved therapeutic properties. Biochim Biophys Acta 1788:1582-1592. 10.1016/j.bbamem.2008.10.020

Samy RP, Thwin MM, Stiles BG, Satyanarayana-Jois S, Chinnathambi A, Zayed ME, Alharbi SA, Siveen KS, Sikka S, Kumar AP, Sethi G, and Lim LH. 2015. Novel phospholipase A2 inhibitors from python serum are potent peptide antibiotics. Biochimie 111:30-44. 10.1016/j.biochi.2015.01.003

Sarojini BK, Krishna BG, Darshanraj CG, Bharath BR, and Manjunatha H. 2010. Synthesis, characterization, in vitro and molecular docking studies of new 2,5-dichloro thienyl substituted thiazole derivatives for antimicrobial properties. European Journal of Medicinal Chemistry 45:3490-3496. http://dx.doi.org/10.1016/i.eimech.2010.03.039

Schwab U, Gilligan P, Jaynes J, and Henke D. 1999. In vitro activities of designed antimicrobial peptides against multidrug-resistant cystic fibrosis pathogens. Antimicrob Agents Chemother 43:1435-1440.

Schweizer HP. 2012a. Mechanisms of antibiotic resistance in Burkholderia pseudomallei: implications for treatment of melioidosis. Future Microbiol 7:1389-1399. $10.2217 / \mathrm{fmb} .12 .116$

Schweizer HP. 2012b. Mechanisms of antibiotic resistance in Burkholderia pseudomallei: implications for treatment of melioidosis. Future Microbiol 7:1389-1399. 10.2217/fmb.12.116

Seo MD, Won HS, Kim JH, Mishig-Ochir T, and Lee BJ. 2012. Antimicrobial peptides for therapeutic applications: a review. Molecules 17:12276-12286. 10.3390/molecules171012276

Sheafor B, Davidson EW, Parr L, and Rollins-Smith L. 2008. Antimicrobial peptide defenses in the salamander, Ambystoma tigrinum, against emerging amphibian pathogens. $J$ Wildl Dis 44:226-236. 10.7589/0090-3558-44.2.226

Sieuwerts S, de Bok FA, Mols E, de vos WM, and Vlieg JE. 2008. A simple and fast method for determining colony forming units. Lett Appl Microbiol 47:275-278. 10.1111/j.1472765X.2008.02417.x

Sim SH, Liu Y, Tan J, Thong TW, Wang D, Ooi EE, and Tan G. 2011. Antimicrobial activity of cathelicidin peptides against Burkholderia pseudomallei, the causative agent of melioidosis. Int J Antimicrob Agents 38:270-271. 10.1016/j.ijantimicag.2011.06.002

Song R, Wei RB, Luo HY, and Wang DF. 2012. Isolation and characterization of an antibacterial peptide fraction from the pepsin hydrolysate of half-fin anchovy (Setipinna taty). Molecules 17:2980-2991. 10.3390/molecules17032980

Stockel S, Meisel S, Elschner M, Melzer F, Rosch P, and Popp J. 2015. Raman spectroscopic detection and identification of Burkholderia mallei and Burkholderia pseudomallei in feedstuff. Anal Bioanal Chem 407:787-794. 10.1007/s00216-014-7906-5

Taweechaisupapong S, Kaewpa C, Arunyanart C, Kanla P, Homchampa P, Sirisinha S, Proungvitaya T, and Wongratanacheewin S. 2005. Virulence of Burkholderia pseudomallei does not correlate with biofilm formation. Microb Pathog 39:77-85. 10.1016/j.micpath.2005.06.001 
Trott O, and Olson AJ. 2010. AutoDock Vina: improving the speed and accuracy of docking with a new scoring function, efficient optimization, and multithreading. J Comput Chem 31:455461. 10.1002/jcc. 21334

Wiersinga WJ, van der Poll T, White NJ, Day NP, and Peacock SJ. 2006. Melioidosis: insights into the pathogenicity of Burkholderia pseudomallei. Nature Reviews Microbiology 4:272-282. 10.1038/nrmicro1385

Wiesner J, and Vilcinskas A. 2010. Antimicrobial peptides: the ancient arm of the human immune system. Virulence 1:440-464. 10.4161/viru.1.5.12983

Wu WK, Sung JJ, To KF, Yu L, Li HT, Li ZJ, Chu KM, Yu J, and Cho CH. 2010. The host defense peptide LL-37 activates the tumor-suppressing bone morphogenetic protein signaling via inhibition of proteasome in gastric cancer cells. J Cell Physiol 223:178-186. 10.1002/jcp.22026

Yonezawa A, Kuwahara J, Fujii N, and Sugiura Y. 1992. Binding of tachyplesin I to DNA revealed by footprinting analysis: significant contribution of secondary structure to DNA binding and implication for biological action. Biochemistry 31:2998-3004. 
Figure 1

Time killing curve of TP1 compared to that of CAZ for B. pseudomallei K96243.

B. pseudomallei K96243 was exposed to TP1 (55 $\mu \mathrm{M}, 110 \mu \mathrm{M}$, and $221 \mu \mathrm{M})$ and CAZ $(54 \mu \mathrm{M})$.

Data was presented as mean and standard deviation of three independent replicates, analyzed with one-way Anova followed by Dunnett's test to determine the significance relative to the untreated bacteria $(P<0.05)$.

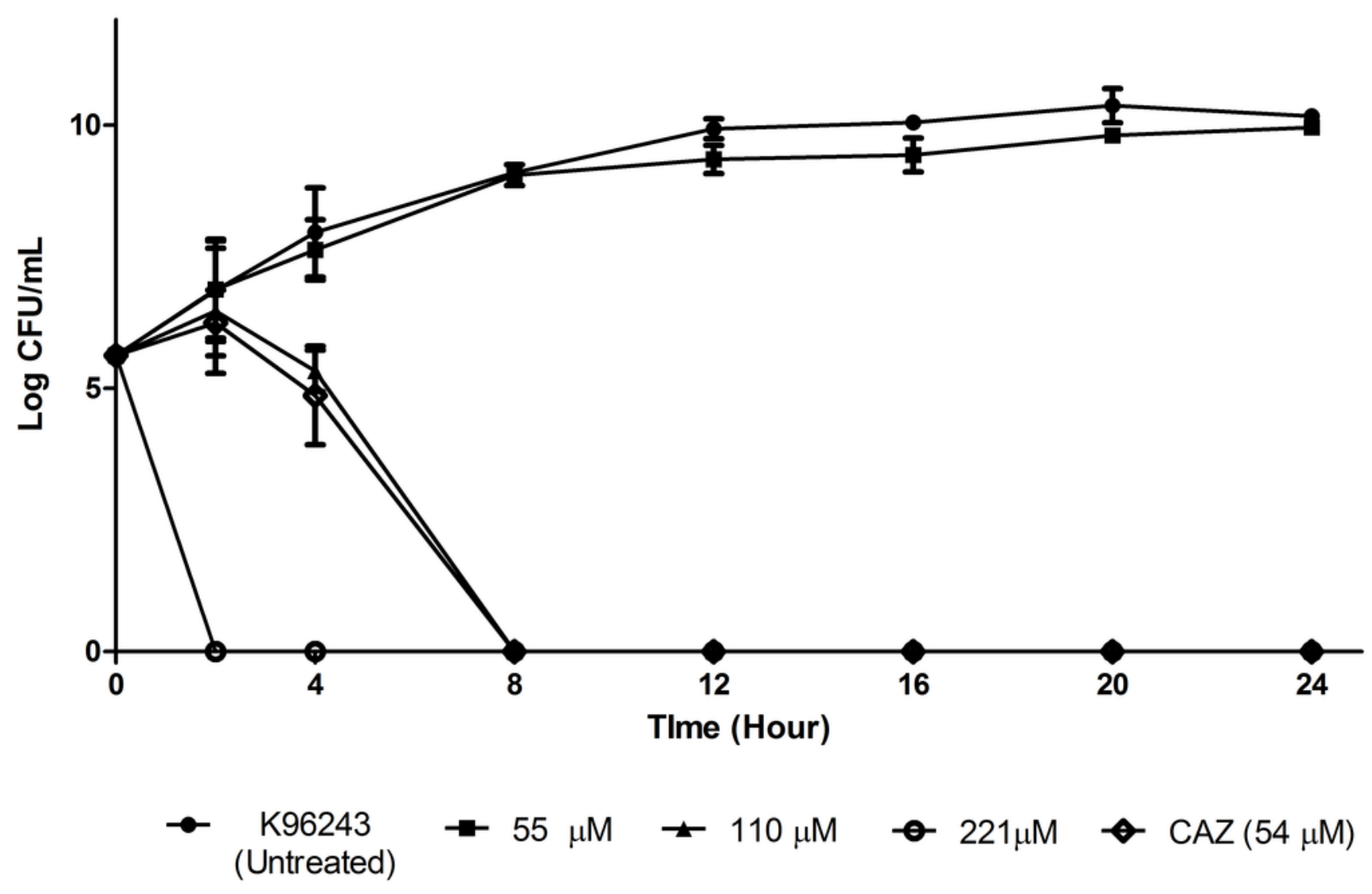


Figure 2

Number of surviving B. pseudomallei K96243 in biofilm state post 24-hour post antimicrobial peptides exposure.

The concentration of antimicrobial agents used were $1 \mathrm{mg} / \mathrm{ml}$. TP1, 1018, PG1, CAZ and MRP showed significant reduction compared to the untreated. These experiments were conducted in three independent replicates. The error bars indicate the standard deviation. One-way Anova followed by Dunnett's test was performed to determine the significance relative to the untreated bacteria $(P<0.05)$, indicated using *

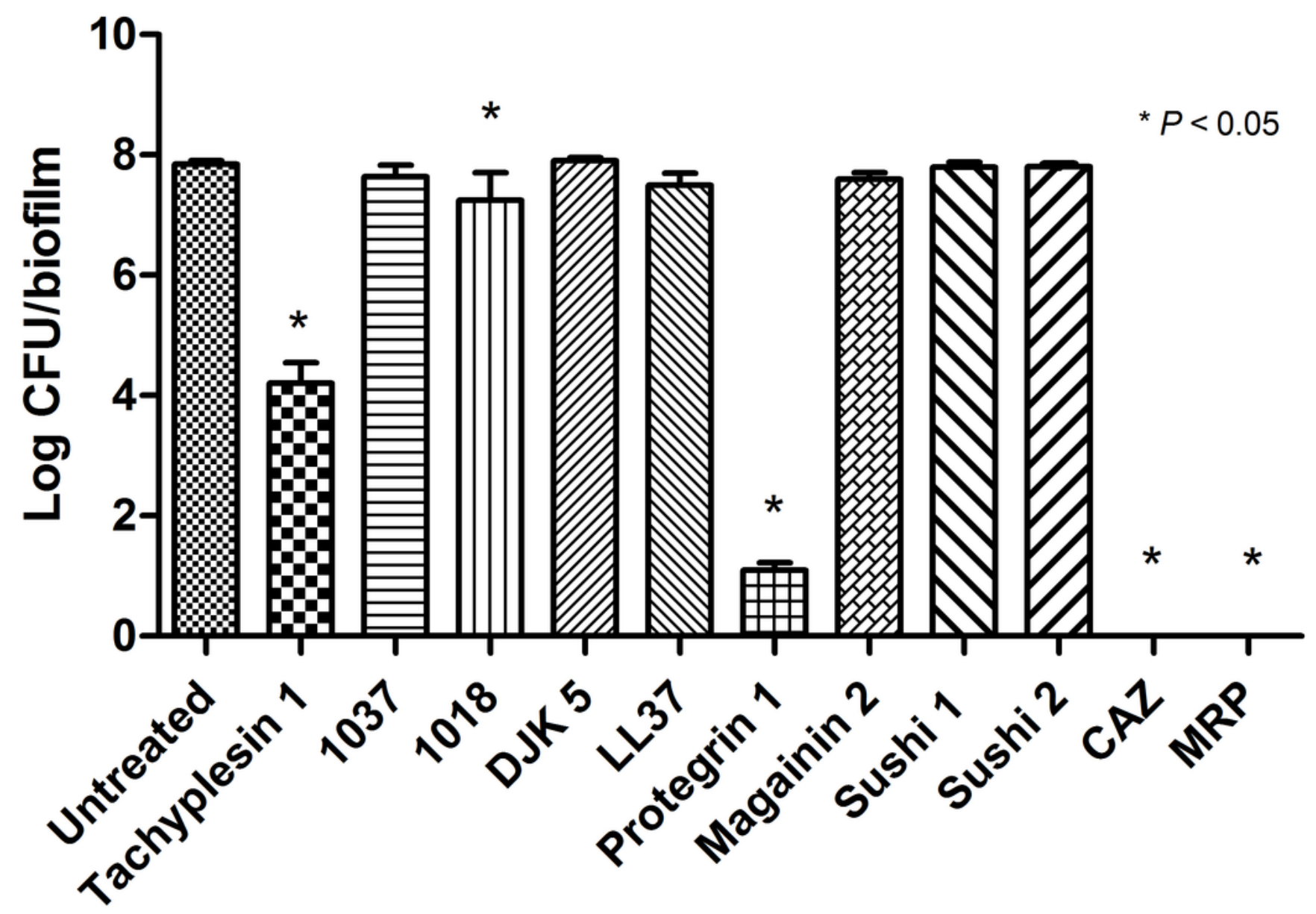

Antimicrobial Agents Tested 
Figure 3

Number of surviving B. pseudomallei $\mathrm{K} 96243$ in a biofilm state 24-hour post-exposure to TP 1

B. pseudomallei K96243 was exposed to different concentrations of TP1 (55 $\mu \mathrm{M}$ to $2649 \mu \mathrm{M}$, with twofold increase). These experiments were performed in three independent replicates where the error bars indicate the standard deviation. Data was analyzed with one-way Anova followed by Dunnett's test to determine the significance relative to the untreated bacteria $(\mathrm{P}<0.05)$, indicated by $*$.

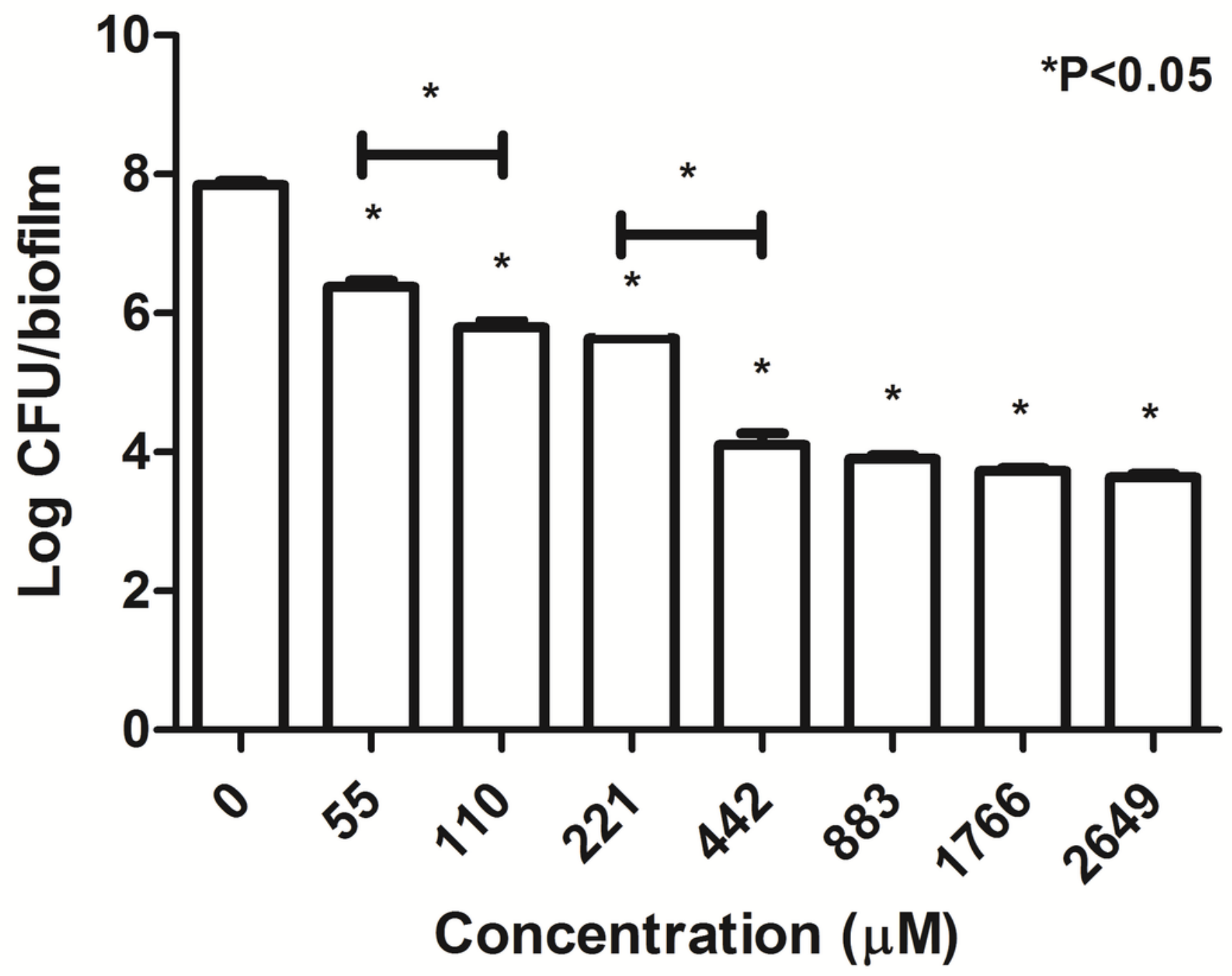




\section{Figure 4}

SEM observation of $B$. pseudomallei K96243 pre- exposure(Panel A)\& postexposure(Panel B) of $62 \mu \mathrm{M} \mathrm{TP1}$ \& E. coli ATCC29522 pre- exposure(Panel C) \& postexposure(Panel D) of $22 \mu \mathrm{M}$ of TP1.

The bacteria samples were fixed on a membrane attached to a double-sided adhesive tape on an SEM stub. Yellow arrows indicate bacterial cell membrane structure before exposure to TP1, blue arrows indicate membrane blebbing, and red arrows indicate cell debris.

*Note: Auto Gamma Correction was used for the image. This only affects the reviewing manuscript. See original source image if needed for review.

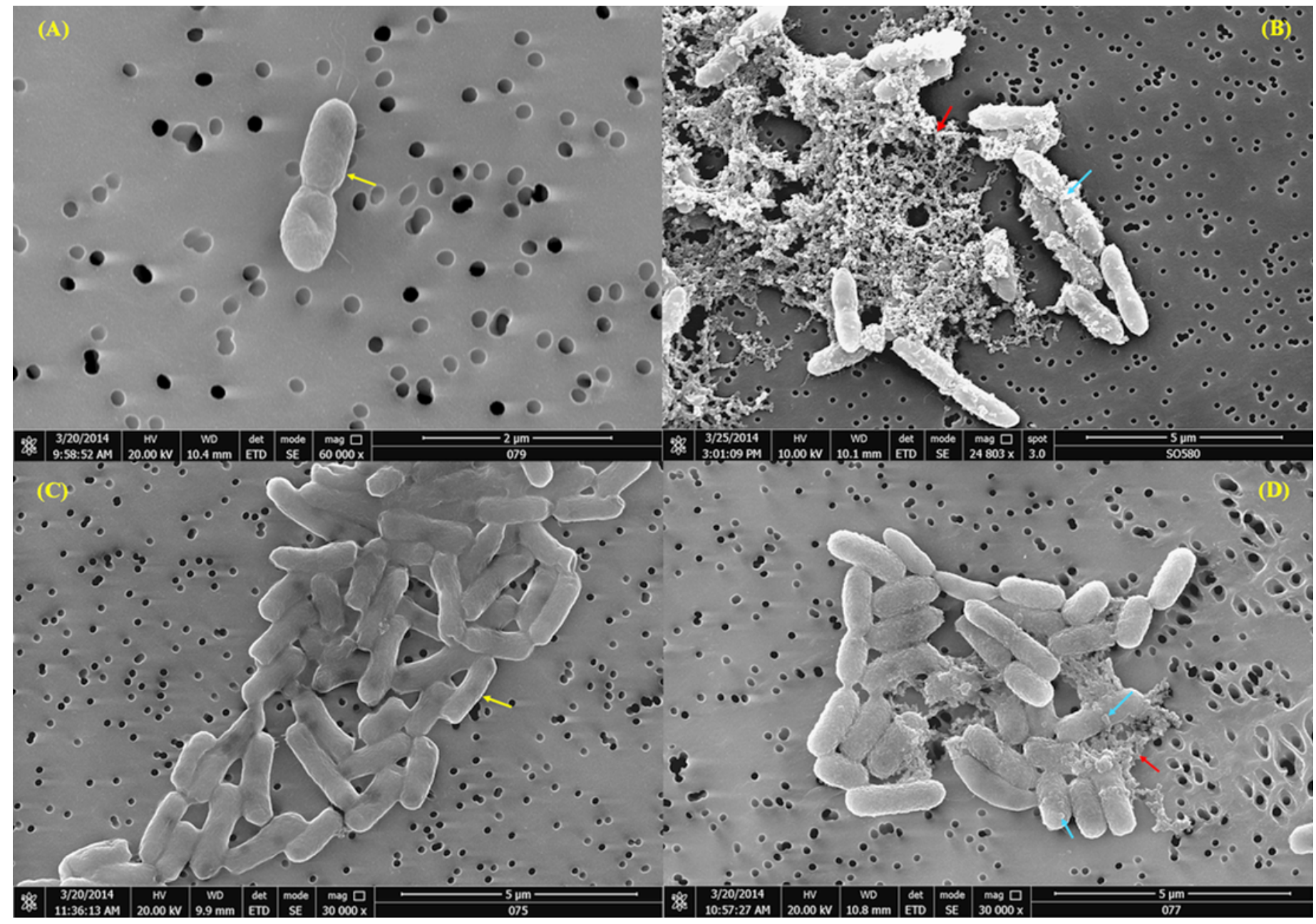


Figure 5

Percentage of viability of A549, HEPG2 and AGS cell lines post-exposure to TP1, PG1, MRP and CAZ.

The cell lines were exposed to TP1 $(0 \mu \mathrm{M}, 2.7 \mu \mathrm{M}, 5.5 \mu \mathrm{M}, 11.0 \mu \mathrm{M}, 22.3 \mu \mathrm{M}, 48.6 \mu \mathrm{M}, 110.4$ $\mu M), \operatorname{PGI}(115 \mu \mathrm{M}), \operatorname{MRP}(26 \mu \mathrm{M})$, and CAZ $(54 \mu \mathrm{M})$. These experiments were conducted in three independent replicates where the error bars indicate the standard deviation. Data was analysed with one-way Anova followed by Dunnett's test to determine the significance relative to the untreated bacteria $(P<0.05$; indicated by $*)$.

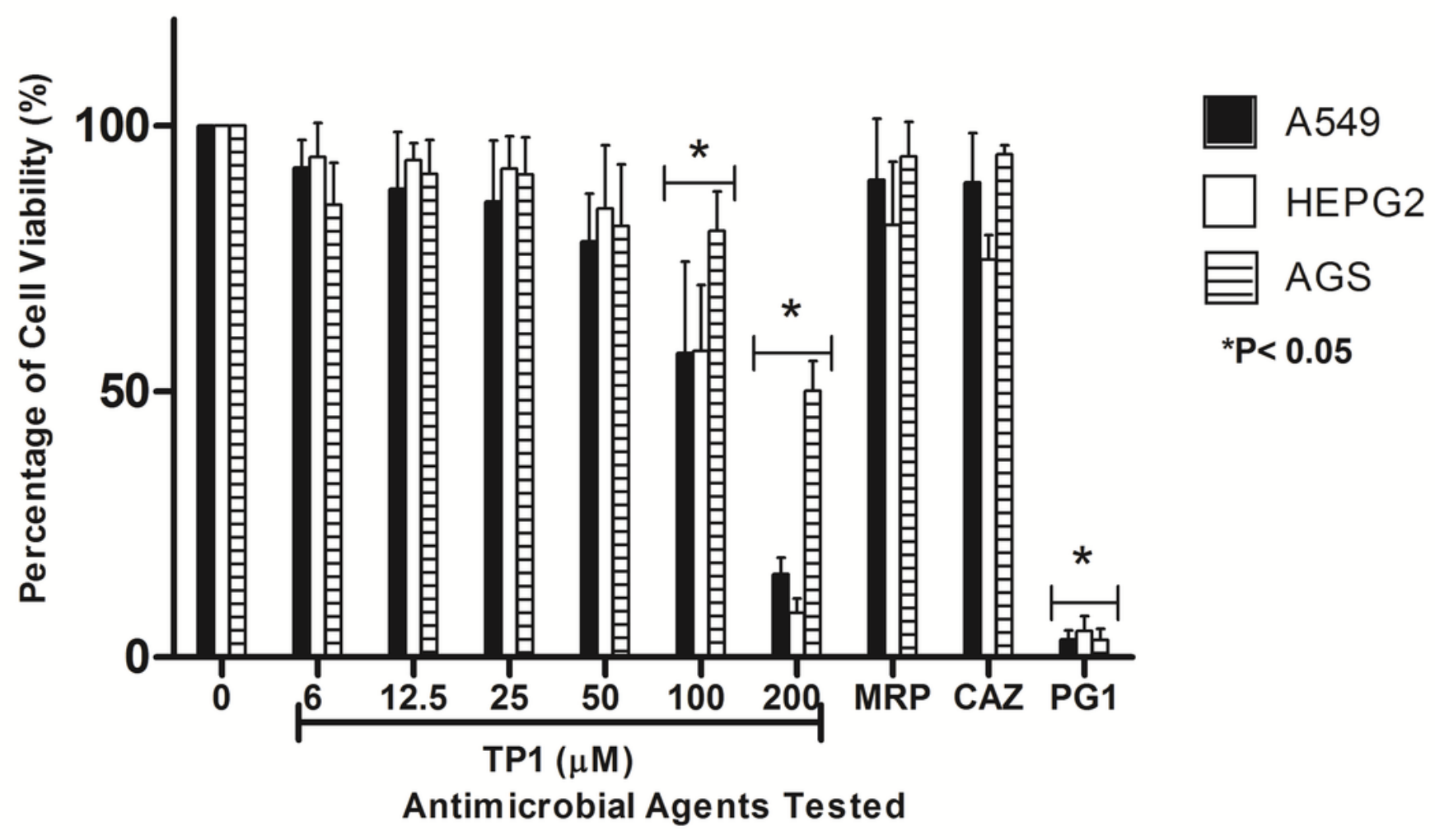




\section{Figure 6}

Graphical representation of LPS of E. coli and TP1 interaction.

Superimposed TP1 was coloured blue while the LPS molecule was coloured grey (Panel A).

The binding amino acids and hydrogen bonds were indicated by green dashes (Panel B). Five hydrogen bonds were formed, mostly at the terminal ends of TP1:ARG15: HH22 - A:

PA11000:04, TP1:ARG17: HE - A: KD01003:07, TP1:ARG17: HE - A: KD01003:08, TP1:ARG17: HH22 - A: KDO1003:08, and A: GLC1007:H6 - TP1:ARG14: 0 


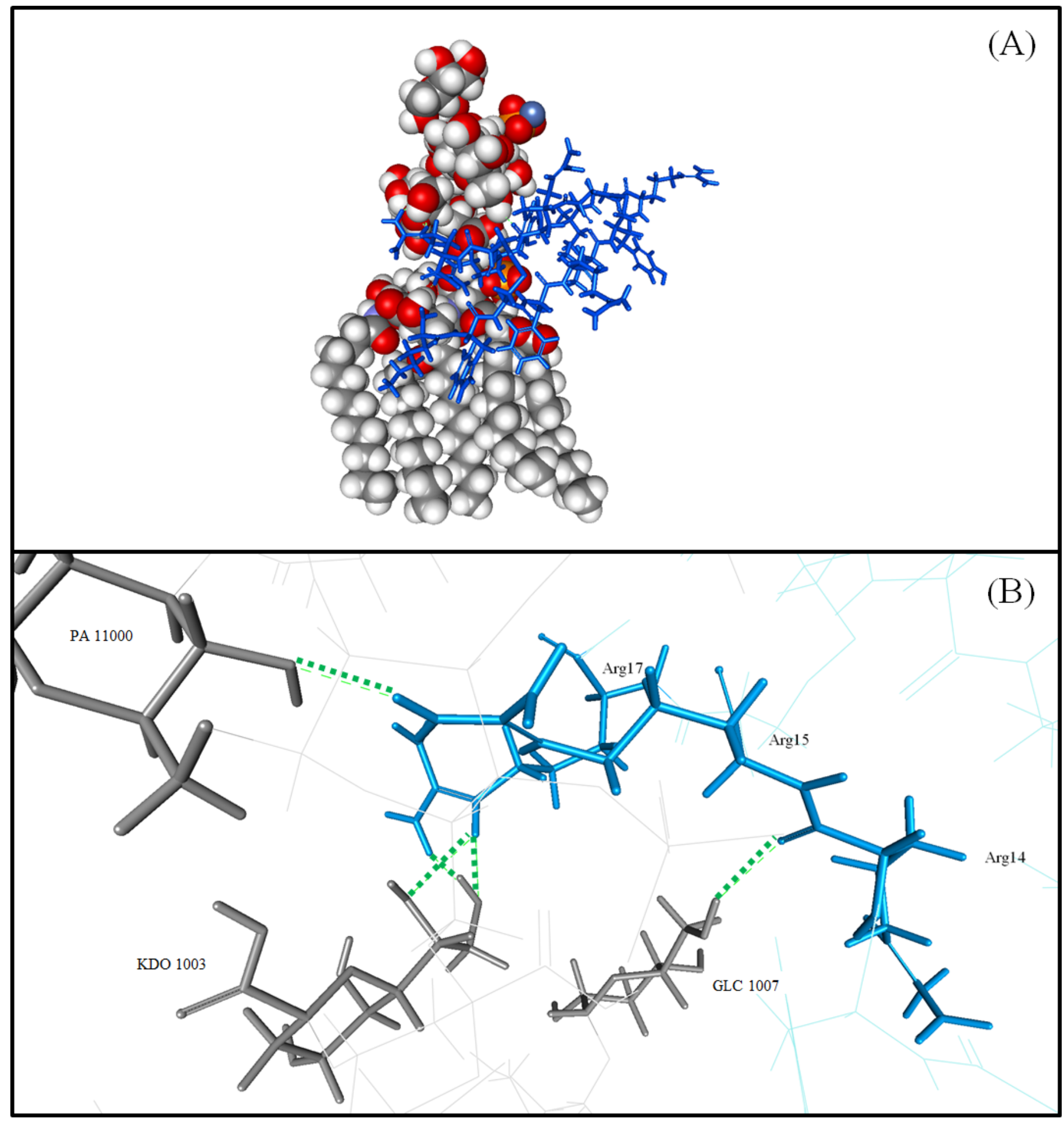




\section{Figure 7}

Graphical representation of YDP model and TP1 interaction.

Superimposed TP1 was coloured blue while YDP model was coloured yellow (Panel A). The binding amino acids and hydrogen bonds were indicated with green dashes (Panel B). Nine hydrogen bonds were observed between TP1 and YDP: TP1:LYS1to YDP: THR1113, TP1:CYS12 to YDP: SER1185, TP1:ARG14 to YDP: ASP1169, TP1:ARG14 to YDP: ASP1169, TP1:ARG14 to YDP: ASP1169, TP1:ARG17 to YDP: ASP1120, YDP: SER1155 to TP1:CYS16, YDP: ARG1157 to TP1:CYS12, and YDP: TYR1166 to TP1:CYS1. 


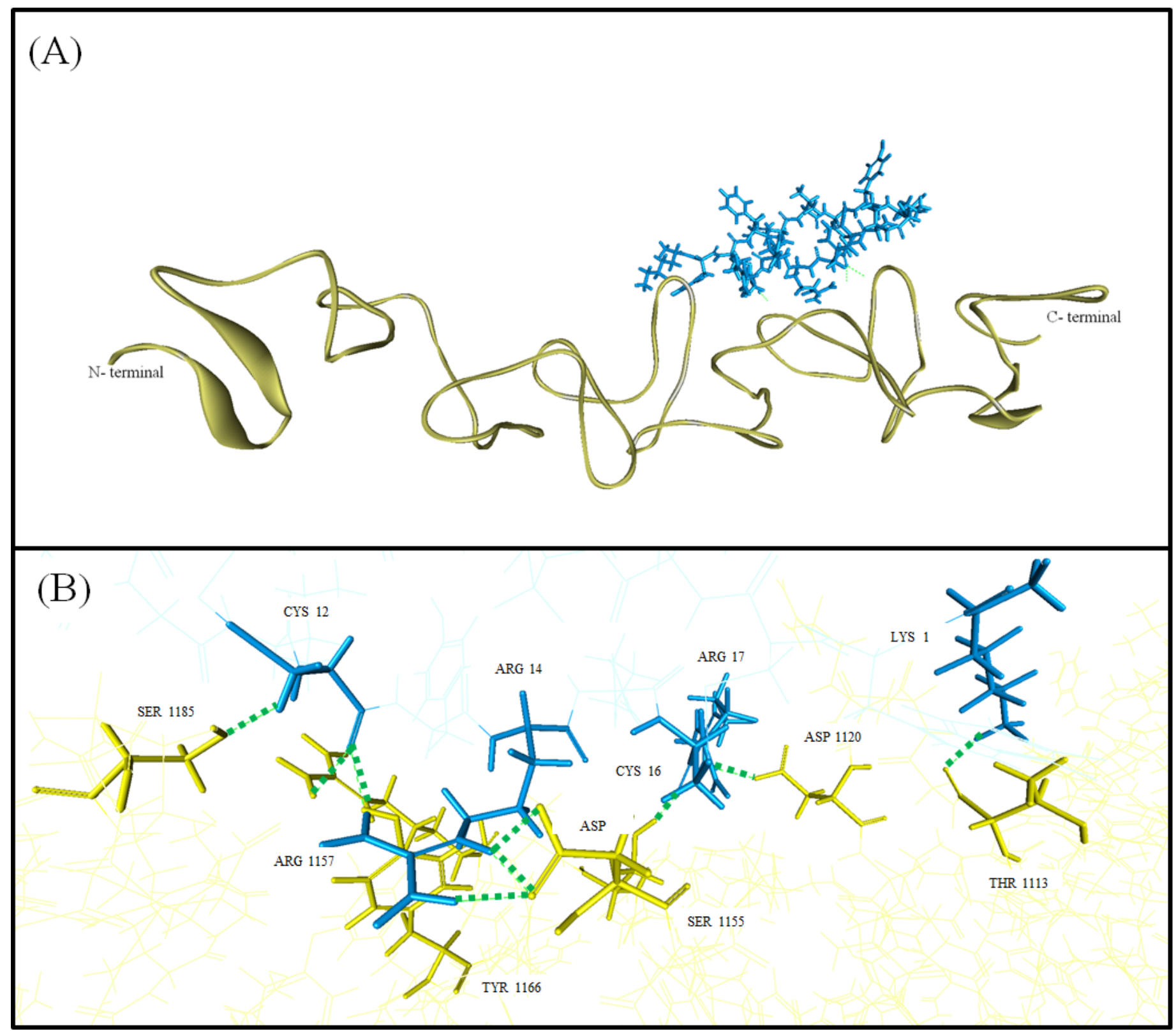




\section{Table 1 (on next page)}

Sequences and characteristics of AMPs investigated 
1 Tables

2 Table 1. Sequences and characteristics of AMPs investigated

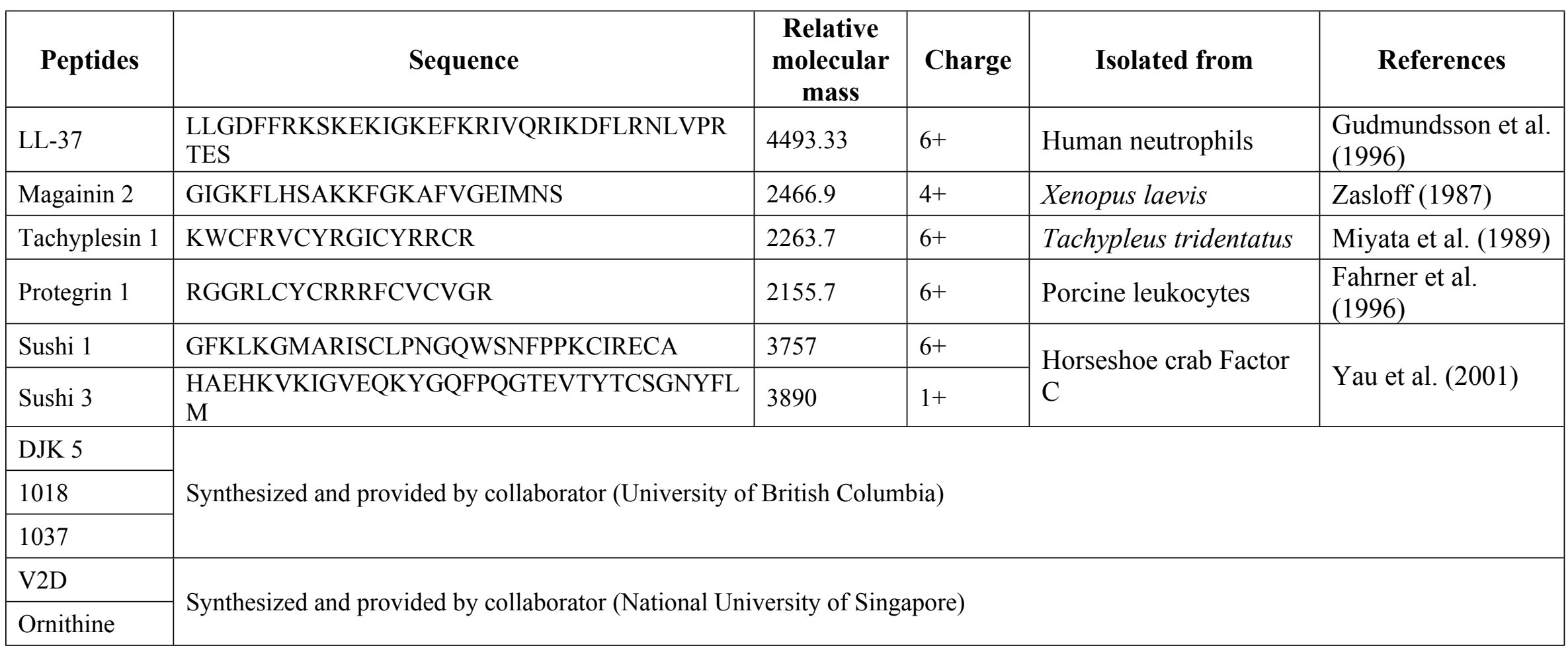




\section{Table 2 (on next page)}

Summary of MIC and MBC values of PG1, LL-37 and TP1 
1 Table 2. Summary of MIC and MBC values of PG1, LL-37 and TP1

\begin{tabular}{|l|l|l|l|l|}
\hline AMP Tested & \multicolumn{2}{|l|}{ B.pseudomallei (average) } & \multicolumn{2}{l|}{ E.coli (ATCC 29522) } \\
\hline & MIC $(\boldsymbol{\mu M})$ & MBC $(\boldsymbol{\mu M})$ & MIC $(\boldsymbol{\mu M})$ & MBC $(\boldsymbol{\mu M})$ \\
\hline Protegrin 1 (Control) & $15.46 \pm 5.02$ & $15.46 \pm 6.70$ & $5.8 \pm 1.09 \mathrm{E}-15$ & $14.24 \pm 2.14$ \\
\hline LL-37 (Control) & $47.29 \pm 8.35$ & $92.73 \pm 8.03$ & $14.8 \pm 6.42$ & $14.8 \pm 6.42$ \\
\hline Tachyplesin 1 & $61.69 \pm 6.38$ & $193.35 \pm 2.00 \mathrm{E}-14$ & $22.1 \pm 0$ & $22.1 \pm 0$ \\
\hline
\end{tabular}

2 


\section{Table 3 (on next page)}

Contribution of the interactions energy in $\mathrm{kcal} / \mathrm{mol}$ of the $E$. coli LPS binding residues with TP1 
1 Table 3: Contribution of the interactions energy in kcal/mol of the E. coli LPS binding residues with TP1

\begin{tabular}{|c|c|c|c|c|c|c|c|}
\hline Residue & $\begin{array}{l}\text { Interaction } \\
\text { Energy } \\
(\mathrm{kcal} / \mathrm{mol})\end{array}$ & $\begin{array}{c}\text { VDW } \\
\text { Interaction } \\
\text { Energy } \\
(\mathrm{kcal} / \mathrm{mol})\end{array}$ & $\begin{array}{c}\text { Electrostatic } \\
\text { Interaction Energy } \\
(\mathrm{kcal} / \mathrm{mol})\end{array}$ & Residue & $\begin{array}{l}\text { Interaction } \\
\text { Energy } \\
(\mathrm{kcal} / \mathrm{mol})\end{array}$ & $\begin{array}{c}\text { VDW } \\
\text { Interaction } \\
\text { Energy } \\
(\mathrm{kcal} / \mathrm{mol})\end{array}$ & $\begin{array}{c}\text { Electrostatic } \\
\text { Interaction Energy } \\
(\mathrm{kcal} / \mathrm{mol})\end{array}$ \\
\hline TP1_LYS1 & -121.19 & -7.95 & -113.24 & 1QFG_PA11000 & -26.62 & -0.15 & -26.47 \\
\hline TP1_TRP2 & -29.60 & -5.32 & -24.29 & 1QFG_GCN1001 & -52.60 & -2.51 & -50.09 \\
\hline TP1_CYS3 & -23.35 & -0.05 & -23.29 & 1QFG_KDO1002 & -44.60 & -5.90 & -38.70 \\
\hline TP1_PHE4 & -25.45 & -5.59 & -19.86 & 1QFG_KDO1003 & -37.97 & -1.86 & -36.11 \\
\hline TP1_ARG5 & -32.65 & -0.19 & -32.46 & 1QFG_GMH1004 & -6.17 & -0.17 & -6.00 \\
\hline TP1_VAL6 & -13.70 & -0.52 & -13.18 & 1QFG_GMH1005 & -32.40 & -1.18 & -31.22 \\
\hline TP1_CYS7 & -13.12 & -0.01 & -13.11 & 1QFG_GLC1006 & -23.80 & -0.35 & -23.45 \\
\hline TP1_TYR8 & -15.07 & 0.00 & -15.06 & 1QFG_GLC1007 & -34.08 & -2.72 & -31.36 \\
\hline TP1_ARG9 & -29.86 & -0.01 & -29.85 & 1QFG_GLA1008 & -1.37 & 0.00 & -1.36 \\
\hline TP1_GLY10 & -26.80 & -0.06 & -26.74 & 1QFG_FTT1009 & -28.99 & -2.56 & -26.43 \\
\hline TP1_ILE11 & -33.80 & -0.51 & -33.29 & 1QFG_FTT1010 & -23.81 & -3.59 & -20.23 \\
\hline TP1_CYS12 & -27.53 & -0.16 & -27.37 & 1QFG_FTT1011 & -24.64 & -2.24 & -22.41 \\
\hline TP1_TYR13 & -47.91 & -7.22 & -40.69 & 1QFG_DAO1012 & -0.16 & -2.61 & 2.45 \\
\hline TP1_ARG14 & -44.16 & -0.45 & -43.71 & 1QFG_FTT1013 & -27.94 & -5.13 & -22.81 \\
\hline TP1_ARG15 & -239.74 & 4.28 & -244.01 & 1QFG_MYR1014 & -35.22 & -4.19 & -31.03 \\
\hline TP1_CYS16 & -28.67 & -0.21 & -28.46 & 1QFG_NI1030 & -48.15 & 0.00 & -48.15 \\
\hline TP1_ARG17 & -85.75 & -3.58 & -82.17 & 1QFG_PO42001 & -356.16 & 7.64 & -363.80 \\
\hline & & & & 1QFG_PO42005 & -33.66 & -0.04 & -33.62 \\
\hline Total & -838.34 & -27.55 & -810.79 & & -838.34 & -27.55 & -810.79 \\
\hline
\end{tabular}

\footnotetext{
* Details of LPS abbreviation are available in Supplementary 4
} 


\section{Table 4(on next page)}

Summary of TP1 interaction with S. pneumoniae protein structures 
1 Table 4: Summary of TP1 interaction with $S$. pneumoniae protein structures

\begin{tabular}{|c|c|c|c|c|c|c|c|}
\hline $\begin{array}{l}\text { Docked } \\
\text { complex }\end{array}$ & $\begin{array}{l}\text { Binding } \\
\text { affinity } \\
(\mathrm{kcal} / \mathrm{mol} \\
)\end{array}$ & $\begin{array}{l}\text { Interactio } \\
\mathrm{n} \text { Energy } \\
\text { (kcal/mol } \\
\text { ) }\end{array}$ & $\begin{array}{l}\text { VDW } \\
\text { Interactio } \\
\mathrm{n} \text { Energy } \\
\text { (kcal/mol } \\
\text { ) }\end{array}$ & $\begin{array}{l}\text { Electrostati } \\
\mathrm{c} \\
\text { Interaction } \\
\text { Energy } \\
(\mathrm{kcal} / \mathrm{mol})\end{array}$ & $\begin{array}{l}\text { No. of } \\
\text { Hydroge } \\
\text { n bonds }\end{array}$ & Hydrogen Bond details & $\begin{array}{l}\text { Additional Intermolecular } \\
\text { Interactions }\end{array}$ \\
\hline $\begin{array}{l}\text { TP1- } \\
\text { autolysin (B) }\end{array}$ & $-8.1(-7.6)$ & -444.17 & -51.03 & -393.14 & 13 & $\begin{array}{l}\text { TP1:LYS1:HT1 - B:ASP246: O } \\
\text { TP1:LYS1:HT2 - B: ASP246:OD2 } \\
\text { TP1:LYS1:HT2 - B:ASP246: O } \\
\text { TP1:LYS1:HT3 - B: ASP246:OD2 } \\
\text { TP1:LYS1: HZ1 - B: VAL279: O } \\
\text { TP1:LYS1: HZ2 - B: MET278: O } \\
\text { TP1:LYS1: HZ3 - B: SER280: OG } \\
\text { TP1:TRP2: HE1 - B: SER280: OG } \\
\text { TP1:ARG15: HH11 - B: SER280: O } \\
\text { TP1:ARG15: HH12 - B: ASN281:OD1 } \\
\text { TP1:ARG15: HH22 - B: ASN281:OD1 } \\
\text { B: LYS274:HZ2 - TP1:ARG5: O } \\
\text { B: LYS274:HZ3 - TP1:ARG5: O }\end{array}$ & None \\
\hline $\begin{array}{l}\text { TP1- } \\
\text { pneumolysin } \\
\text { (P) }\end{array}$ & $-7.7(-6.2)$ & -135.59 & -37.62 & -97.97 & 9 & $\begin{array}{l}\text { TP1:ARG14: HH22 - P: GLU434:OE2 } \\
\text { TP1:ARG15: HE - P: ASN400:OD1 } \\
\text { TP1:ARG15: HH21 - P: ASN400:OD1 } \\
\text { TP1:ARG15: HH21 - P: ASN400: O } \\
\text { TP1:ARG17: HH12 - P: ASP380:OD2 } \\
\text { TP1:ARG17: HH21 - P: THR378:OG1 } \\
\text { TP1:ARG17: HH22 - P: THR378:OG1 } \\
\text { P: LYS424:HZ1 - TP1:ARG17: O }\end{array}$ & $\begin{array}{l}\text { Pi- Cation: } \\
\text { P: TRP433 - TP1:ARG9:NE } \\
\text { P: TRP433 - TP1:ARG9:NE }\end{array}$ \\
\hline
\end{tabular}




\begin{tabular}{|c|c|c|c|c|c|c|c|}
\hline & & & & & & P: GLU434:HN - TP1:GLY10: O & \\
\hline TP1-pspA & $-7.3(-6.4)$ & -573.48 & -46.10 & -527.38 & 8 & $\begin{array}{l}\text { TP1:LYS1: HZ2 - pspA: ASN571: O } \\
\text { TP1:TRP2: HE1 - pspA: TYR546: OH } \\
\text { TP1:GLY10:HN - pspA: LYS580: O } \\
\text { TP1:TYR13: HH - pspA: ASP573: } \\
\text { OD2 } \\
\text { TP1:ARG15: HH21 - pspA: ASN542: } \\
\text { O } \\
\text { TP1:ARG15: HH21 - pspA: ASN542: } \\
\text { O } \\
\text { TP1:ARG17: HH22 - pspA: ASN542: } \\
\text { O } \\
\text { pspA: ASN569:HD21 - TP1:TYR13: } \\
\text { OH }\end{array}$ & $\begin{array}{l}\text { Pi-Pi: } \\
\text { PspA: TYR541 - TP1:TRP2 } \\
\text { Pi- Cation: } \\
\text { pspA: TRP525 - TP1:LYS1:NZ } \\
\text { pspA: TRP518 - TP1:LYS1: N } \\
\text { pspA: TRP518 - TP1:LYS1: N } \\
\text { pspA: TRP518 - TP1:LYS1:NZ } \\
\text { Pi-Sigma: } \\
\text { pspA: TRP518 - TP1:LYS1: HB1 }\end{array}$ \\
\hline
\end{tabular}




\section{Table 5 (on next page)}

Contribution of the interactions energy in $\mathrm{kcal} / \mathrm{mol}$ of the homology modelled $B$. pseudomallei protein (YDP) binding residues with TP1 
Table 5: Contribution of the interactions energy in $\mathrm{kcal} / \mathrm{mol}$ of the homology modelled B. pseudomallei protein (YDP) binding

2 residues with TP1

\begin{tabular}{|c|c|c|c|c|c|c|c|}
\hline Residue & $\begin{array}{l}\text { Interaction } \\
\text { Energy } \\
(\mathrm{kcal} / \mathrm{mol})\end{array}$ & $\begin{array}{l}\text { VDW Interaction } \\
\text { Energy } \\
(\mathrm{kcal} / \mathrm{mol})\end{array}$ & $\begin{array}{l}\text { Electrostatic } \\
\text { Interaction Energy } \\
(\mathrm{kcal} / \mathrm{mol})\end{array}$ & Residue & $\begin{array}{l}\text { Interaction } \\
\text { Energy } \\
(\mathrm{kcal} / \mathrm{mol})\end{array}$ & $\begin{array}{l}\text { VDW Interaction } \\
\text { Energy } \\
(\mathrm{kcal} / \mathrm{mol})\end{array}$ & $\begin{array}{l}\text { Electrostatic } \\
\text { Interaction Energy } \\
(\mathrm{kcal} / \mathrm{mol})\end{array}$ \\
\hline TP1_LYS1 & -158.78 & -6.00 & -152.78 & $\begin{array}{l}\text { YDP } \\
\text { MODEL_THR1113 }\end{array}$ & -26.00 & -1.90 & -24.10 \\
\hline TP1_TRP2 & -39.15 & -4.41 & -34.74 & $\begin{array}{l}\text { YDP } \\
\text { MODEL_GLY1114 }\end{array}$ & -9.83 & -0.89 & -8.94 \\
\hline TP1_CYS3 & -22.10 & -0.41 & -21.69 & $\begin{array}{l}\text { YDP } \\
\text { MODEL_ASN1115 }\end{array}$ & -5.55 & -2.25 & -3.31 \\
\hline TP1_PHE4 & -15.84 & -0.22 & -15.62 & $\begin{array}{l}\text { YDP } \\
\text { MODEL ARG1119 }\end{array}$ & 115.99 & -7.04 & 123.03 \\
\hline TP1_ARG5 & -43.61 & -0.24 & -43.37 & $\begin{array}{l}\text { YDP } \\
\text { MODEL_ASP1120 }\end{array}$ & -209.81 & -0.04 & -209.77 \\
\hline TP1_VAL6 & -1.99 & -0.12 & -1.87 & $\begin{array}{l}\text { YDP } \\
\text { MODEL_MET1121 }\end{array}$ & -22.28 & -0.85 & -21.43 \\
\hline TP1_CYS7 & -16.13 & -0.66 & -15.47 & $\begin{array}{l}\text { YDP } \\
\text { MODEL_ASN1152 }\end{array}$ & -13.83 & -0.39 & -13.44 \\
\hline TP1_TYR8 & -3.87 & -0.64 & -3.23 & $\begin{array}{l}\text { YDP } \\
\text { MODEL LEU1153 }\end{array}$ & -15.54 & -1.94 & -13.59 \\
\hline TP1_ARG9 & -37.61 & -1.29 & -36.32 & $\begin{array}{l}\text { YDP } \\
\text { MODEL_SER1155 }\end{array}$ & -18.76 & -2.36 & -16.39 \\
\hline $\begin{array}{l}\text { TP1_GLY1 } \\
0\end{array}$ & -19.93 & -1.69 & -18.24 & $\begin{array}{l}\text { YDP } \\
\text { MODEL_ALA1156 }\end{array}$ & -9.01 & -1.78 & -7.23 \\
\hline TP1_ILE11 & -6.20 & -2.93 & -3.27 & $\begin{array}{l}\text { YDP } \\
\text { MODEL_ARG1157 }\end{array}$ & 3.56 & -6.45 & 10.01 \\
\hline $\begin{array}{l}\text { TP1_CYS1 } \\
2\end{array}$ & -19.07 & -5.30 & -13.77 & $\begin{array}{l}\text { YDP } \\
\text { MODEL_TYR1166 }\end{array}$ & -13.50 & -2.83 & -10.67 \\
\hline $\begin{array}{l}\text { TP1_TYR1 } \\
3\end{array}$ & -56.36 & -4.94 & -51.42 & $\begin{array}{l}\text { YDP } \\
\text { MODEL_GLY1167 }\end{array}$ & -12.56 & -0.52 & -12.04 \\
\hline $\begin{array}{l}\text { TP1_ARG1 } \\
4\end{array}$ & -160.54 & -11.89 & -148.65 & $\begin{array}{l}\text { YDP } \\
\text { MODEL_TYR1168 }\end{array}$ & -13.56 & -3.68 & -9.88 \\
\hline $\begin{array}{l}\text { TP1_ARG1 } \\
5\end{array}$ & -67.65 & -1.55 & -66.10 & $\begin{array}{l}\text { YDP } \\
\text { MODEL_ASP1169 }\end{array}$ & -190.00 & -5.01 & -184.99 \\
\hline $\begin{array}{l}\text { TP1_CYS1 } \\
6\end{array}$ & -29.17 & -3.82 & -25.35 & $\begin{array}{l}\text { YDP } \\
\text { MODEL ASN1171 }\end{array}$ & -14.29 & -0.88 & -13.41 \\
\hline TP1_ARG1 & -124.82 & -6.07 & -118.74 & YDP & 2.96 & -0.34 & 3.30 \\
\hline
\end{tabular}




\begin{tabular}{|l|l|l|l|l|r|r|r|}
\hline 7 & & & & MODEL_LEU1177 & & \\
\hline & & & & $\begin{array}{l}\text { YDP } \\
\text { MODEL_ASP1179 }\end{array}$ & -81.10 & -2.25 & -78.86 \\
\hline & & & $\begin{array}{l}\text { YDP } \\
\text { MODEL_PRO1180 }\end{array}$ & -20.33 & -3.95 & -16.39 \\
\hline & & & $\begin{array}{l}\text { YDP } \\
\text { MODEL_SER1185 }\end{array}$ & -21.11 & -4.17 & -16.94 \\
\hline & & & $\begin{array}{l}\text { YDP } \\
\text { MODEL_ARG1223 }\end{array}$ & -12.49 & -12.09 \\
\hline Total & & & & & & & \\
\hline
\end{tabular}

